Accepted Manuscript

OR in Spare Parts Management: A Review

Qiwei Hu , John E. Boylan, Huijing Chen, Ashraf Labib

PII:

S0377-2217(17)30701-4

DOI:

10.1016/j.ejor.2017.07.058

Reference:

EOR 14608

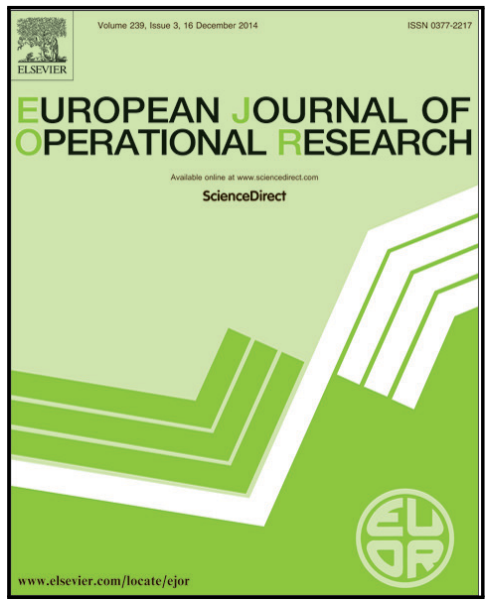

To appear in:

European Journal of Operational Research

Received date:

Revised date:

18 April 2016

Accepted date:

21 July 2017

24 July 2017

Please cite this article as: Qiwei Hu, John E. Boylan, Huijing Chen, Ashraf Labib, OR in Spare Parts Management: A Review, European Journal of Operational Research (2017), doi: 10.1016/j.ejor.2017.07.058

This is a PDF file of an unedited manuscript that has been accepted for publication. As a service to our customers we are providing this early version of the manuscript. The manuscript will undergo copyediting, typesetting, and review of the resulting proof before it is published in its final form. Please note that during the production process errors may be discovered which could affect the content, and all legal disclaimers that apply to the journal pertain. 


\section{European Journal of Operational Research Manuscript Draft}

\section{Manuscript Number:}

Title: OR in Spare Parts Management: A Review

\section{Article Type:}

Keywords: inventory, spare parts management, operational research (OR)

Corresponding Author: Huijing Chen

Corresponding Author's Institution: University of Portsmouth

First Author: Qiwei Hu

Order of Authors: Qiwei Hu, John E Boylan, Huijing Chen, Ashraf Labib

Abstract: Spare parts are held to reduce the consequences of equipment downtime, playing an important role in achieving the desired equipment availability at a minimum economic cost. In this paper, a framework for OR in spare parts management is presented, based on the product lifecycle process and including the objectives, main tasks, and OR disciplines for supporting spare parts management. Based on the framework, a systematic literature review of OR in spare parts management is undertaken, and then a comprehensive investigation of each OR discipline's contribution is given. The gap between theory and practice of spare parts management is investigated from the perspective of software integration, maintenance management information systems and adoption of new OR methods in software. Finally, as the result of this review, an extended version of the framework is proposed and a set of future research directions is discussed. 


\section{Cover letter}

Dear Editor-in-Chief,

Please find attached our manuscript entitled "OR in Spare Parts Management: A Review", to be considered for publication in the European Journal of Operational Research. The objective of this paper is to carry out a systematic literature review of OR in spare parts management according to a framework for OR in spare parts management, established based on the product lifecycle process. We have included in this submission the following items:

- This Cover Letter.

-The full-text in PDF (3rd revision).

-Highlights.

We provide below the list of authors, their affiliations and contact details.

Yours sincerely,

Dr. Huijing Chen

On behalf of Dr. Qiwei Hu, Prof John E Boylan and Prof. Ashraf Labib

\section{Authors affiliations and contact details:}

\section{Dr. Qiwei Hu}

Department of Management Engineering, Mechanical Engineering College, Shijiazhuang, 050003, China; and Portsmouth Business School, University of Portsmouth, Richmond Building, Portland Street, Portsmouth, PO1 3DE, UK.

Telephone: +44 (0) 239284 4025. Email: hu_q_w@163.com; qiwei.hu@ port.ac.uk

\section{Prof. John E Boylan}

Department of Management Science, Lancaster University, LA1 4YX, UK

Telephone: +44 (0) 152459 4425. Email: j.boylan@lancaster.ac.uk

\section{Dr. Huijing Chen}

Portsmouth Business School and Centre for Operational Research \& Logistics , University of 
Portsmouth, Richmond Building, Portland Street, Portsmouth PO1 3DE, UK.

Telephone: +44 (0) 239284 4025. Email: huijing.chen1@port.ac.uk

\section{Prof. Ashraf Labib}

Portsmouth Business School and Centre for Operational Research \& Logistics , University of Portsmouth, Richmond Building, Portland Street, Portsmouth PO1 3DE, UK.

Telephone: +44 (0) 239284 4729. Email: ashraf.labib@port.ac.uk

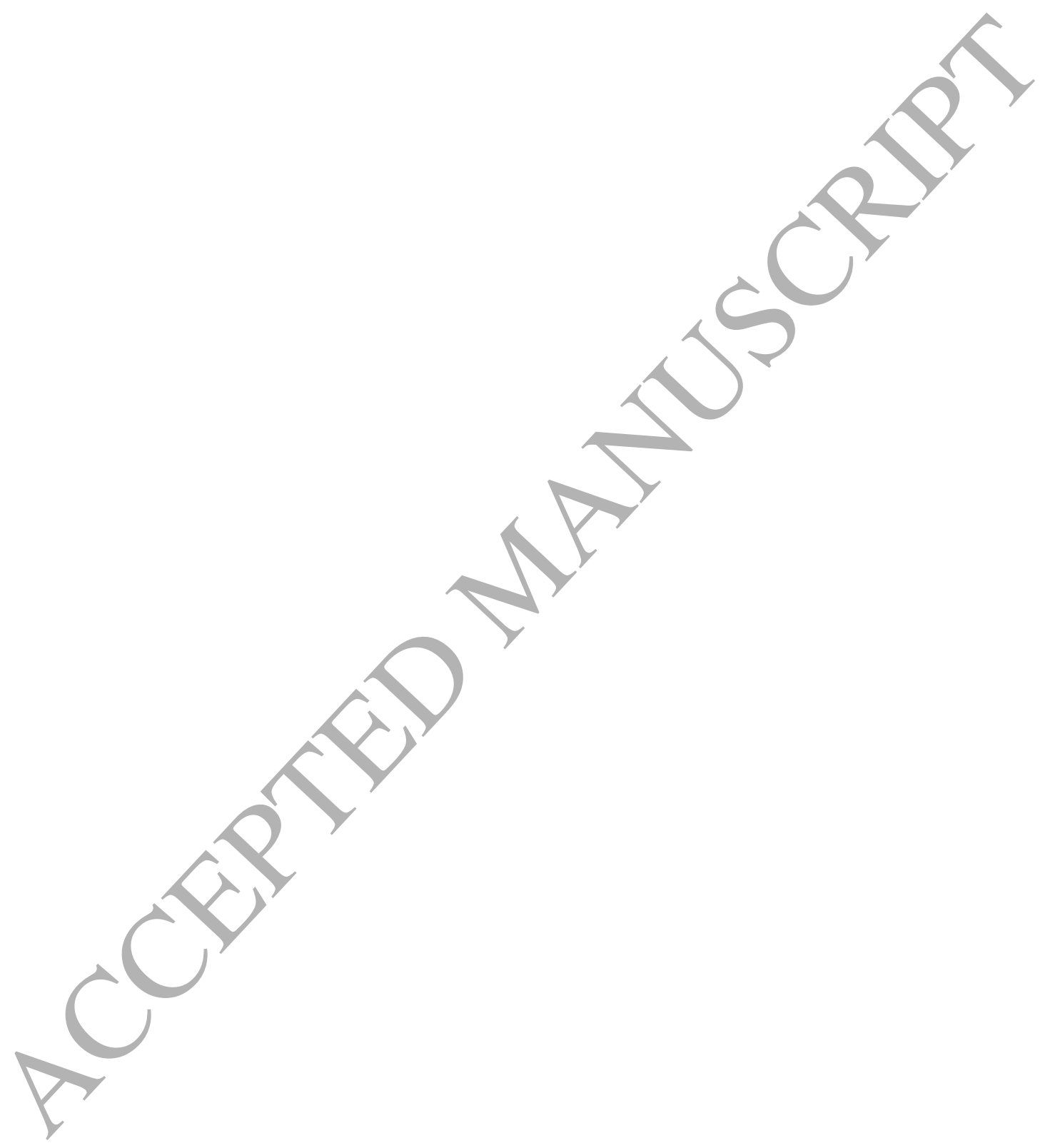




\section{Highlights}

This is a general review focusing on OR in spare parts management.

A new framework is presented from a product lifecycle process perspective.

222 contributions are reviewed and issues identified for each OR discipline.

Emerging research directions and application gaps are presented.

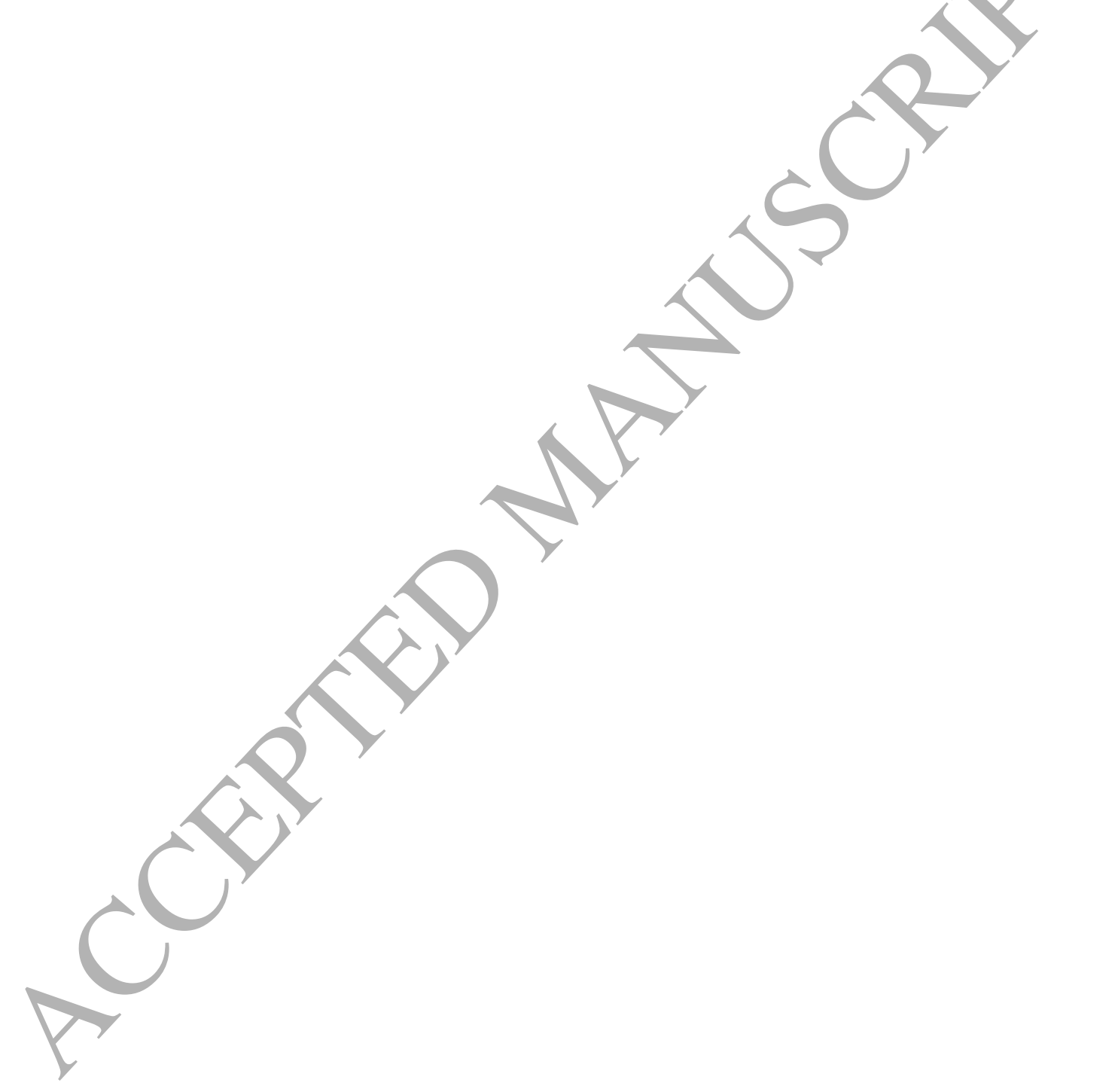




\title{
OR in Spare Parts Management: A Review
}

\author{
Qiwei $\mathrm{Hu}^{1,3}$, John E Boylan ${ }^{2}$, Huijing $\mathrm{Chen}^{3, *}$, Ashraf Labib ${ }^{3}$
}

1. Department of Management Engineering, Shijiazhuang Mechanical Engineering College, Shijiazhuang, 050003, China. Email: hu_q_w@163.com

2. Department of Management Science, Lancaster University, LA1 4YX, United Kingdom. Email: j.boylan@lancaster.ac.uk

3. Department of Operations and Systems Management, Portsmouth Business School, University of Portsmouth, Portsmouth, PO1 3DE, United Kingdom. Email: \{huijing.chen1, ashraf.labib\} @ port.ac.uk

*Corresponding author. Huijing Chen; Telephone: +44 (0)2392844025; Email: huijing.chen1 @ port.ac.uk

\begin{abstract}
Spare parts are held to reduce the consequences of equipment downtime, playing an important role in achieving the desired equipment ayailability at a minimum economic cost. In this paper, a framework for OR in spare parts management is presented, based on the product lifecycle process and including the objectives, main tasks, and OR disciplines for supporting spare parts management. Based on the framework, a systematic literature review of OR in spare parts management is undertaken, and then a comprehensive investigation of each OR discipline's contribution is given. The gap between theory and practice of spare parts management is investigated from the perspective of software integration, maintenance management information systems and adoption of new OR methods in software. Finally, as the result of this review, an extended version of the framework is proposed and a set of future research directions is discussed.
\end{abstract}

Keywords: inventory, spare parts management, operational research (OR)

\section{Introduction}

Spare parts are common inventory stock items, which are needed to maintain equipment. It has been observed that the cost of spare parts takes a large share of product lifecycle cost. Machinery, which might have a useful life of up to 30 years, annually consumes spare parts amounting to as much as 2.5 percent of the purchase price (Gallagher et al. (2005)). The non-availability of spare parts, as and when 
required for repairs, will result in great financial loss, especially for those industries with sophisticated technologies, aiming for mass and continuous production. Therefore, spare parts management plays an important role in achieving the desired equipment availability at a minimum cost.

The management of spare parts is often considered to be a special case of general inventory management with some peculiar characteristics, which makes it especially difficult. There are four such characteristics of spare parts, which are of particular importance. Firstly, intermittent demand patterns are common among spare parts. They are characterized by sequences of zero demand observations interspersed by occasional non-zero demands (e.g. Boylan \& Syntetos (2010)). So, spare parts demand is very difficult to forecast. Secondly, the number and variety of spare parts are usually very large. It is common to observe companies of even moderate sizes carrying thousands of different items in inventory (e.g. Guvenir \& Erel (1998)). In this situation, it is difficult to identify an appropriate stock control strategy for each spare part, thereby posing a significant challenge for inventory management. Thirdly, in order to reduce the risk of spare parts' obsolescence, it is particularly important to minimize stocks, with only a small quantity per Stock Keeping Unit (SKU) kept in store. In this case, if the stock strategy is improperly determined, it may result in heavy penalties of excess stock costs (associated with the SKUs) or costs of equipment downtime. Fourthly, the consumption of spare parts is closely related to maintenance. A spare part is needed when the corresponding part of the equipment fails, is damaged or wears out. This dependence on equipment usage is made more challenging by the number and criticality of spare parts within certain equipment, and subsequently the criticality of the equipment with respect to the whole production system (Labib \& Exton (2001), Exton \& Labib (2002)). So, the usage patterns of equipment and their maintenance strategies are important foundations in designing spare parts supply systems.

These unusual aspects of spare parts have led many researchers to throw themselves into this challenging research field. Many Operational Research (OR) models have been proposed, and a variety of software solutions have been developed in the past few decades. However, there is a lack of a comprehensive critical review of OR models in this area. Some previous works have reviewed academic research on spare parts management. Silver (1981) undertook a broad review of OR in inventory management. Other review papers covered selected topics in inventory management. Kennedy et al. (2002) reviewed research papers on management issues, age-based replacement, multi-echelon problems, problems involving obsolescence, repairable spare parts, and special applications. Boylan and Syntetos (2009) focused their review on forecasting for spare parts 
management, while Syntetos et al. (2009a) reviewed the literature on forecasting for inventory planning. Paterson et al. (2011) reviewed research on inventory models with lateral transshipments. Bacchetti et al. (2012) carried out a literature review of spare parts classification and demand forecasting, and investigated the gap between research and practice in spare parts management. Bakker et al. (2012) undertook a review of recent research on inventory systems with deterioration. Basten \& Van Houtum (2014) reviewed contributions relating to system-oriented inventory models for spare parts. Syntetos et al. (2016) provided a comprehensive review of the literature in supply chain forecasting. Many of these contributions reviewed research on general stock keeping units (SKUs) instead of focusing on spare parts. By contrast, this paper provides a contribution to spare parts management which is different from the above literature reviews in that: i), it is a more general review of OR in spare parts management, drawing on a wide variety of OR approaches; ii) a new framework is proposed for OR in spare parts management; and iii) a critique is presented of applications of OR theory through software packages.

The remainder of this paper is organized as follows: Section 2 presents a framework for spare parts management, highlighting the main issues and the contributions of OR disciplines in supporting spare parts management; Sections 3-6 contain an analysis of the literature on four critical aspects of OR in spare parts management, namely: i) spare parts classification, ii) demand forecasting, iii) inventory optimization, and iv) supply chain system simulation; in Section 7, an overview on applications of the theory is presented through an evaluation of software for spare parts management; Section 8 gives some concluding remarks and future research directions.

\section{Framework for OR in Spare Parts Management}

In this section, we present a new framework for OR in spare parts management to help to structure our review of a complex area. One may ask why a new framework is needed at all, as there have been two frameworks for spare parts management proposed in the last ten years (Cavalieri et al. (2008), Driessen etal. (2015)). Cavalieri et al. (2008) focused mainly on inventory control and Driessen et al. (2015) focused on processes and decisions that need to be made at tactical and operational levels. Our framework, in comparison, has a broader focus and covers strategic as well as tactical and operational levels. It covers the major objectives of spare parts management, the OR disciplines to support the achievement of these objectives, and the phases of the product life cycle in which these disciplines may be applied. The emphasis on the product life cycle recognizes that the priorities for spare parts management change through the cycle, and the tasks to be supported by OR models change 
accordingly. The concept of the product life cycle is well established (e.g. Rink and Swan (1979); Klepper (1996)), and it is important for the purpose of this review to include the whole cycle. Most research papers are restricted to the normal operation phase, but there is also a body of OR literature which addresses the earlier and later phases. Distinguishing three phases of the life cycle is not new. However, its combination with the dimension of OR disciplines, overlaid by objectives, is a new development.

This is a descriptive framework, in which well-established research themes are housed. In this review, the aim is not only to summarize those areas which have been well researehed, but also to highlight areas that have been less thoroughly investigated. These new and potentially valuable research themes and directions are included in the extended framework in Section 8. Those themes with relatively few papers are included in the extended framework, in order to encourage more work in these areas.

The new framework is shown in Figure.1. It is to be read top-down, and includes three layers: i) objectives of spare parts management, ii) main tasks through the phases of the equipment lifecycle process, and iii) OR disciplines for supporting spare parts management. The cells in the middle show detailed tasks that need to be done and the arrows indicate the phases in which they are performed. The cells may be regarded as sub-tasks of the main tasks, shown in Layer 2. They may also be seen as applications of the OR disciplines shown on the left-hand-side of the framework or, indeed, as sub-tasks of the main requirements of/classification, forecasting and optimization. If viewed as sub-tasks, however, it should be acknowledged that simulation is often used in conjunction with other analytical OR disciplines. For example, the task of optimization may require the use of both classical optimization techniques and simulation methods.

$\mathrm{D}$ refers to design and $\mathrm{P}$ to provisioning. In this paper, we use two different terms for design: system design and equipment design. System design refers to the design issues in a spare parts management system. This definition of design is included in the descriptive framework. Such design activities can be carried out using various OR techniques. For example, multi-criteria classification is used to categorize demand while simulation is a useful tool to experiment with alternative systems before deciding on the best. In the extended framework, the idea of equipment design is also incorporated to highlight the need to have a spare parts strategy when designing capital equipment. Provisioning is the implementation of the designed spare parts management system. 


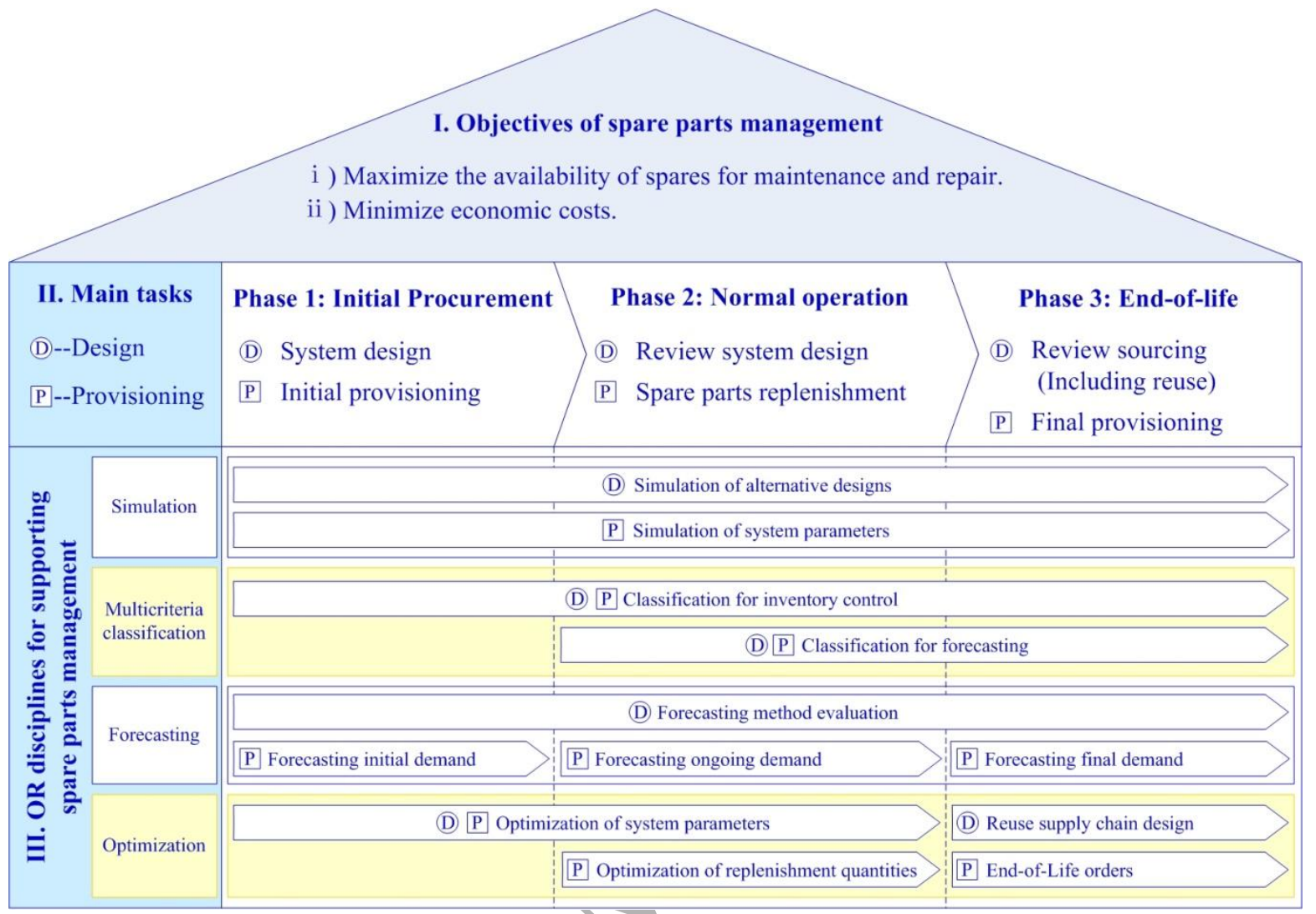

Figure.1 Descriptive Framework for OR in spare parts management

\subsection{Layer I: Objectives of spare parts management}

The key questions in spare parts management are to decide which items are to be stocked as spare parts, when to (re)order them and how many items to (re)order. In this decision-making process, we should be clear about the objectives. Most of the literature is dominated by two objectives, namely maximizing spares' availability, and minimizing the economic costs. Here, the economic costs are generally taken as the sum of the inventory holding costs, stock-out penalty costs and ordering costs (although, for expensive parts, the ordering costs may be insignificant).

\subsection{Layer II: Main tasks of spare parts management through equipment lifecycle process}

Equipment life cycle cost is closely connected to investment and management of spare parts inventories. In general, the equipment lifecycle process can be divided into three main phases, namely initial procurement phase, normal operation phase, and end-of-life phase. The main tasks of spare parts management for each phase of the product lifecycle process are summarized below.

Initial procurement phase: When a complicated piece of equipment is bought, spare parts are often 
bought simultaneously to satisfy the needs of equipment maintenance. Then a decision must be made on the spare parts initial provisioning, and an inventory and forecasting system must be designed in advance.

Normal operation phase: When equipment is used by the user, preventive maintenance may be carried out to prevent failure, while corrective maintenance is carried out as failures occur (See Cheng \& Tsao (2010) for analytical approaches to deciding on the best maintenance strategy). In order to satisfy the needs of maintenance, a certain number and kinds of spare parts are supplied. Successful equipment management depends on the proper execution of spare parts control. Therefore, the inventory system and forecasting parameters should be optimized (or at least improved) to provide sustainable supply support according to the operational requirements of the equipment.

End-of-life phase: In Phase 3, a fundamental issue of supply chain design is whether products, or their components, should be reused, leading to refurbishment or remanufacturing, If not, then it may sometimes be necessary to set a final order on spare parts according to the demand patterns at the end of the product life cycle (known as an 'all-time buy' or 'last-time buy'). This prompts a number of design issues to be resolved, including the methodologies for classifying and forecasting the demand, taking into account that no more orders may be made, and simulating the consequences of alternative strategies for these parts in the end-of-life phase.

\subsection{Layer III: OR disciplines for supporting spare parts management}

A broad range of techniques is needed for facilitating spare parts management. With respect to OR, there are four main kinds of technical approaches, namely multi-criteria classification, forecasting, optimization, and simulation. In the framework shown in Figure.1, each of these four approaches is further mapped against each phase of the equipment lifecycle process.

Simulation: Simulation is defined as experimentation with a simplified imitation of an operations system as it progresses through time, for the purpose of better understanding and/or improving that system (Robinson (2004)). According to the different purposes of simulating a spare parts supply system, we divide it into two groups: i) assessing alternative designs when a spare parts supply system is designed or improved; ii) simulation of system parameters when making decisions on spare parts provisioning. In carrying out these design and provisioning tasks, simulation can be applied alongside the following three OR disciplines. There will be areas of overlapping, particularly with optimization, in performing the provisioning tasks. This will be discussed further in Section 6 .

Multicriteria classification: Spare parts classification is an essential part of spare parts management. 
Different requirements for classification have led to different types of spare parts classifications. We divide inventory classification into two groups, namely classification for inventory control and classification for forecasting. The first classification is used to select an appropriate stocking policy for different groups of spare parts when designing a spare parts supply system, and then to undertake inventory control by classifying spare parts into groups. The second classification is used to select appropriate forecasting method for different groups of parts, for the normal operation and end-of-life phases, and then to undertake forecasting by using the classification accordingly. We use the term "multi-criteria classification" as this is the most general approach. We also consider the special case in which a single criterion is constructed from multiple criteria.

Forecasting: Forecasting demand is an important operational issue, and has always been a major challenge of spare parts management. There are design issues in each phase, specifying the range of methods available for initial, normal and final phases. This recognizes that the application of each forecasting method is limited because the available data and the factors influencing spare parts demand are different in different phases of the lifecycle. For example, there is little historical spare parts consumption data to use in the initial procurement phase, while more data can be accumulated with the passage of time in the normal operation phase. Obsolescence will occur in the end-of-life phase, during which remanufacturing of used or obsolescent products can be an alternative source of gaining spare parts. Therefore, the right range of methods must be specified for each phase (a design issue) and the right methods must be selected and implemented to inform provisioning.

Optimization: In order to achieve high availability of spare parts with minimum investment, we may use inventory optimization techniques to balance capital investment and service-level constraints or objectives over a large assortment of spare parts. Here, inventory optimization differs over the three phases of the lifecycle, namely: i) optimizing system parameters, which takes place when new equipment is introduced, ii) optimizing replenishment quantities, which occurs during the normal operation phase, and iii) optimizing end-of-life orders and reuse supply chain design, which are used to satisfy the need for equipment maintenance during the final phase of the life cycle process.

In the next four sections, we provide a summary of the main contributions for each of the OR disciplines supporting spare parts management, as outlined in this section. Therefore, the reviewed research is divided into several groups and sub-groups according to the framework shown in Figure.1. This is not only to facilitate reading, but also to highlight gaps for both researchers and practitioners.

\section{Multicriteria classification}


It is common practice to group spare parts for effective inventory management according to some classification method. In the past few decades, various approaches have been proposed to address the multiple criteria inventory classification (MCIC) problem. Considering its different application purposes we divide MCIC methods into two groups as shown in Figure.1: i) classification for inventory control, and ii) classification for forecasting.

\subsection{Classification for inventory control}

Classification of spare parts permits the identification of the most important spare parts. Then managers can use different inventory strategies for different classes of spare parts, and prioritize the most important items in spare parts management.

Multiple criteria ABC classification: Historically, organizations have classified spare parts into A, $\mathrm{B}$, and $\mathrm{C}$ groups, called $\mathrm{ABC}$ classification, based on one single criterion, namely annual cost usage of the spare part, which is calculated as spare part cost multiplied by demand volume. However, there are many other criteria not considered in $\mathrm{ABC}$ classification, and a single criterion cannot capture the many dimensions of spare parts management. An early contribution was a multiple criteria $\mathrm{ABC}$ classification scheme proposed by Flores \& Whybark $(1986,1987)$. We have found 34 research papers published on this topic since then, and many classification approaches have been applied to MCIC, as shown in Appendix A. Among them, fourteen (Guvenir \& Erel (1998), Flores \& Whybark (1986, 1987), Partovi \& Burton (1993), Partovi \& Anandarajan (2002), Bhattacharya et al. (2007), Cakir \& Canbolat (2008), Chu et al. (2008), ÇEbi et al. (2010), Rezaei \& Dowlatshahi (2010), Hadi-Vencheh \& Mohamadghasemi (2011), Lolli et al. (2014), Park et al. (2014), Hu et al. (2017)) have carried out case studies with real-world applications. Furthermore, Appendix A shows that almost all approaches (with the exception of the Analytic Hierarchy Process or AHP, and Dominance-based Rough Set Approach (DRSA)) have been proposed in one paper only, with no follow up papers developing the ideas further or testing the approaches empirically. Therefore, almost all of the proposed classification approaches require further empirical evaluation.

In Appendix A, most of the research papers applied classification approaches to common inventory classification, therefore we will not provide further details on them but interested readers can refer to them directly. We focus on the eight contributions (Guvenir \& Erel (1998), Flores \& Whybark (1986, 1987), Partovi \& Burton (1993), Partovi \& Anandarajan (2002), Chu et al. (2008), Rezaei \& Dowlatshahi (2010), Hu et al. (2017)) that have carried out case studies applied to spare parts classification. Based on them, we divide the ABC classification criteria, which were employed in them, 
into three groups as shown in Appendix B. It can be observed that there are various classification criteria which have been employed differently from equipment to equipment and in different application areas. The most commonly employed criteria are lead time and criticality, followed by annual cost usage and unit price. Thus, case-study evidence indicates that lead-time and criticality reflect important dimensions of supply and demand in practice.

Categorizing spare parts into A, B, and C groups facilitates spare parts inventory management, especially for companies which have tens of thousands of spare parts. Nevertheless, most research on ABC classification has concentrated on developing classification methods, and only three contributions (Mohammaditabar et al. (2012), Zhang et al. (2001), Teunter et al. (2010)) addressed linking ABC classification to the selection of a stocking strategy. Mohammaditabar et al. (2012) proposed an integrated model that concurrently classifies inventory items and selects appropriate policies for each product group with the objective of effective inventory performance. The proposed model was compared with annual dollar usage (ADU), AHP weighted score, the method proposed by Zhang et al. (2001) and optimal inventory score, and exceeded all of them in minimizing both dissimilarity and total inventory value. Two other papers classified spare parts into ABC groups incorporating selection of stocking strategies. Zhang et al. (2001) developed a new ABC classification criterion, which is a ratio taking into account expected demand per year, lead time, and unit cost. Based on the new criterion, the determination of reorder points and reorder quantities was investigated. A numerical study showed that the proposed ABC scheme did not introduce large errors. Teunter et al. (2010) proposed a further new cost criterion for ABC classification. The criterion takes four system parameters into account, namely demand rate, holding cost (purchase price), shortage cost (criticality), and average order quantity. Based on classification results using the new criterion, the cycle service level for each class/can then be fixed, where the A group should have the highest service level, followed by B and then by C. A numerical experiment using three real life datasets showed that the proposed criterion outperformed the criterion proposed by Zhang et al. (2001).

Classification and choice of inventory system: Since classification and stocking strategy selection should be linked together to provide an effective inventory control policy, some papers have challenged the traditional $\mathrm{ABC}$ classification scheme and have explored new classifications for better managing spare parts. All of the reviewed papers below are related to integration of new spare parts classification and selection of the best stocking strategy. We divide this review into two parts: i) fixed number of classification groups and ii) optimal number of classification groups. 
i) Fixed number of classification groups. In addition to the $\mathrm{ABC}$ classification, some papers present other classification groups. Botter \& Fortuin (2000) employed a VED (vital, essential, and desirable) classification approach to make decisions on which items should be stocked based on two criteria, functionality and demand rate. Then the stocking strategies about where and how many to be stocked were further explored based on the classification. Huiskonen (2001) discussed distinct operating policies for different types of spare parts, as well as showing the links between the part characteristics and logistics system elements. Labib \& Exton (2001) and Exton \& Labib (2002) proposed a Decision Making Grid (DMG) technique for selecting an appropriate stocking strategy based on the two criteria of frequency of withdrawing spares from stores and an item's criticality to production. Braglia et al. (2004) developed a decision diagram to classify spare parts based on a new classification with respect to multiple attributes, including spare parts plant criticality, spare supply characteristics, inventory problems, and usage rates. Molenaers et al. (2012) proposed a spare part classification method based on item criticality, which is calculated by taking into account equipment criticality, probability of item failure, replenishment time, number of potential suppliers, availability of technical specifications, and maintenance type, by means of the AHP method. Then, stock strategies are determined based on the new classification scheme. Bacchetti et al. (2013) proposed a hierarchical multi-criteria classification method to divide spare parts into 12 different classes and identify inventory management policies for the 12 classes.

ii) Optimal number of classification groups. Different from the above classification schemes with a fixed number of classes, some papers proposed methods to optimize the number of classification/groups based on multiple objectives. Chakravarty (1981) considered a more general problem setting and showed that the optimal grouping can be obtained by ordering the items according to the product of demand rate and holding cost rate. Tsai \& Yeh (2008) presented a particle swarm optimization approach to determine the optimal number of inventory classes where inventory items are classified based on a specific objective or multiple objectives. By virtue of the flexibility in terms of item group numbers and objectives, it facilitates determining the optimal stocking strategies. Millstein et al. (2014) proposed a mixed-integer linear programming (MILP) model to optimize ABC inventory grouping decisions. The proposed model can optimize the number of inventory groups, their 
corresponding service levels and assignment of SKUs to groups, under a limited inventory spending budget.

\subsection{Classification for forecasting}

Different spare parts are associated with different underlying demand patterns, which in turn require different forecasting methods (e.g. Heinecke et al. (2013)). So a classification with respect to extrapolative time-series based demand forecasting methods may be based on a classification based on demand patterns. We have found 13 contributions (Williams (1984), Johnston \& Boylan (1996), Syntetos (2001), Ghobbar \& Friend (2003), Eaves (2002), Eaves \& Kingsman (2004), Syntetos et al. (2005), Boylan et al. (2008), Kostenko \& Hyndman (2006), Syntetos et al. (2012), Heinecke et al. (2013), Syntetos et al. (2013), Van Wingerden et al. (2014)) about this kind of classification published to date.

The first study to address this issue was conducted by Williams (1984) who developed a classification scheme for the effective management of SKUs in a public utility in the United Kingdom (UK). The proposed classification scheme classifies demand for SKUs into 'smooth', 'slow-moving', and 'sporadic' categories based on an idea called variance partition, the purpose of which was the identification of the most appropriate forecasting and inventory control methods for the resulting categories. Johnston and Boylan (1996) reconceptualized the term 'intermittence' by evaluating the conditions under which a forecasting method designed for intermittent demand (Croston's method) outperformed a method designed for non-intermittent demand (Single Exponential Smoothing, SES). The authors recommended a rule that if the mean inter-demand interval is greater than 1.25 forecast review periods, then Croston's method should be used rather than SES. Syntetos (2001) modified Williams' model (1984) to classify demand patterns into four categories (intermittent, slow moving, erratic and lumpy demand) using the average demand interval $(A D I)$ and square coefficient of variation of demand sizes $\left(C V^{2}\right)$. Ghobbar \& Friend (2003) classified spare parts according to the Syntetos (2001) method in their case study, and it was shown that the impact of demand variability, using $C V^{2}$ and $A D I$, on forecast errors is significant. Eaves (2002) and Eaves \& Kingsman (2004) also modified Williams' model (1984) to analyze inventory data from the Royal Air Force (RAF), reclassifying spare parts in five categories, namely smooth, irregular, slow moving, slightly intermittent and highly intermittent. Compared with Eaves (2002) and Eaves \& Kingsman (2004), Syntetos (2001) provided a classification method with broad applicability instead of applying it in a specific case study. Afterwards, Syntetos, Boylan \& Croston (2005) (hereafter SBC) presented this 
method in order to establish the cut-off values for the two classification criteria $\left(p=1.25\right.$ and $C V^{2}=$ 0.49), which were assessed in tests with 3,000 real-intermittent demand data series from the automotive industry. Boylan et al. (2008) carried out an empirical investigation to assess the SBC scheme through a case study of a UK-based software manufacturer, and demonstrated the insensitivity of the $p$ cut-off value, for classification purposes, in the approximate range of 1.18-1.86 periods. Less tangible conclusions were derived for the $C V^{2}$ criterion, although this was finally adopted as a classification parameter by the company in the case-study. In order to improve overall forecasting accuracy, Kostenko \& Hyndman (2006) (hereafter KH) developed an extension of the SBC scheme. Heinecke et al. (2013) assessed the empirical performance of the fixed cut-off values rule suggested by SBC and the linear function proposed by KH. The KH function provided slight accuracy gains over SBC (see Table 6 of Heinecke et al, 2013); the effect on stock control performance was not assessed in the study. Syntetos et al. $(2012,2013)$ explored the potential linkages between the SBC scheme and demand distributional assumptions on a demand per period basis. They conducted a detailed empirical investigation for a specific company on the goodness-of-fit of various distributions and their stock control implications in terms of inventories held and service levels achieved. The linkage between demand distributions and demand categories is often implicit in software applications (eg normal distribution for A and B items, Poisson distribution for C items) but has only recently been studied systematically by academic researchers. Van Wingerden et al. (2014) agreed with Boylan et al. (2008) that $p$ and $C V^{2}$ were the most important characteristics to classify demand. They also used average lead time, average demand size and price in their empirical analysis. Van Wingerden et al. (2014) concluded that for parts with a high $p$ and low $C V^{2}$ it was best to use the empirical plus method, which the authors proposed and was based on Porras and Dekker (2008), whilst for other classes of parts SBA was the best.

\subsection{Remarks}

In this section, we presented a review on multiple criteria inventory classification, including the special case of a single criterion constructed from multiple criteria. Although most research papers tend to focus on the $\mathrm{ABC}$ classification, there are others which investigate the integration of spare parts classification to the selection of a stocking strategy, as well as classification for forecasting. Based on the above analysis, we can summarize as follows:

Firstly, we should attach more importance to the development of demand categorization in the academic research of spare parts management. Demand categorization rules dictate the forecasting and 
stock control methods to be used for different SKUs. Consequently, these rules have significant implications in terms of stock and customer satisfaction. Nevertheless, demand categorization has attracted limited academic interest. More theoretical and empirical research is much needed in this area.

Secondly, we remark that there is an obvious limitation of $\mathrm{ABC}$ classification in that it always groups spare parts into just three classes no matter how varied the spare parts may be. We identified only three papers arguing that an optimized number of classification groups is beneficial when a stocking strategy is selected through spare parts classification. More work would appear to be merited in this area, to develop these optimized approaches further and evaluate their benefits over a fixed number of demand categories.

Finally, most of the existing MCIC methods need to be further developed and validated through empirical studies. Although many MCIC methods have been proposed, most have not been subject to further academic debate or evaluation. Some researchers carried out an analysis using only example data extracted from other contributions or through a simulation study. Seldom have classification schemes been evaluated using real-world applications. It should be acknowledged that such evaluations are not necessarily straightforward for the following four reasons. i) The purpose of the classification must be clarified, whether it is to inform the stock/no stock decision, the ordering rule to employ, or the forecasting method to use. ii) Clarity is needed in research papers on the performance measures that are intended to be improved by the use of the classification scheme, which may include accuracy and inventory measures. In classification for forecasting, appropriate choices of accuracy measures should be made. To facilitate comparison of results across different data sets, scale independent measures (see, for example, Fildes (1992)) should be chosen. Examples include relative error measures, which are formulated as a ratio of forecast accuracy using Classification Method A and Classification Method B. iii) Appropriate benchmark classifications should be compared with any new approach, including a benchmark of no classification to ensure that classification is genuinely needed. iv) The classification rules, and the subsequent inventory or forecasting methods to be used for each method, should be specified in sufficient detail to allow reproduction of results and replication of findings. (See Boylan et al. (2015) for a discussion of reproducibility in the context of forecasting methods). It is important that these four issues are addressed. If they are not, then it is very difficult to assess the value of a classification approach. On the other hand, if the goals, measures, and comparator approaches are clear, and research studies are reproducible, then a body of evidence can be developed 
on the relative performance of classification schemes.

\section{Forecasting}

Forecasting spare parts demand is a basic requirement of spare parts management. Because of the demand characteristics of spare parts, it is very difficult to accurately forecast demand in this area. Boone et al. (2008) carried out a Delphi study on the critical challenges of inventory management in service parts by interviewing 18 senior service part managers from different industries, and identified that the inaccuracy of service parts forecasts ranks number two in the top ten challenges. So it has been a hot topic in the industrial field as well as in academic research.

There are many forecasting techniques and this section restricts attention to those forecasting methods which have been suggested for spare parts. From a product lifecycle perspective, there are three kinds of forecasting tasks shown in Figure.1, namely forecasting initial demand, ongoing demand and demand over the final phase. In order to facilitate the literature review, we may categorize forecasting approaches into three groups according to the type of forecasting technique: time-series, reliability and judgmentally based forecasting. Time-series based forecasting can be applied to forecast ongoing demand and demand over the final phase, but can rarely be used to forecast initial demand because there is little historical spare parts consumption data when new equipment is introduced. Reliability based forecasting can be used throughout the whole lifecycle process as long as the reliability and maintenance characteristics are known or may be estimated. Judgmentally based forecasting is used to forecast spare parts demand according to managers' experience, and can also be used throughout the whole lifecycle process. It is often used when there is neither time-series data nor reliability and maintenance characteristics available, especially in the initial phase of the lifecycle. It is also used to adjust the forecasting results when qualitative information is available that is not being taken into account by a quantitative model.

The following literature review of forecasting spare parts demand is organized following the categorization of time-series, reliability, and judgmentally based forecasting approaches.

\subsection{Time-series based forecasting}

A time series is defined as a time-ordered sequence of observations taken at regular intervals (e.g., hourly, daily, weekly, monthly, quarterly, annually). Time-series forecasting is based on the assumption that future values of the series can be estimated from past values (e.g. Stevenson (2012)). If there is ample historical data, time-series based forecasting is commonly used to forecast spare parts demand in practice. 
Forecasting methods: The traditional methods, commonly used in practice to forecast spare parts demand, were designed for faster-moving items. They are mainly based on Exponential Smoothing and include Holt's Method for trended data, damped Holt's for damped-trended data, and the Holt-Winters' method for data that is trended and seasonal. Although such methods are relatively simple (compared to approaches such as Auto-Regressive Integrated Moving Averages, for example), there is empirical evidence from forecasting competitions showing that they may achieve good accuracy in practice (M1 Competition, Makridakis et al. (1982); M3 Competition, Makridakis \& Hibon (2000)). However, many (if not most) spare parts are slow-moving items, often having periods with no demand at all. Such items are known as 'intermittent' and were not included in the M1 or M3 Competitions. The standard forecasting method for intermittent demand items is considered to be Croston's (CR) method (Syntetos \& Boylan (2005)). Syntetos and Boylan (2001) showed that Croston's estimator is biased, and proposed a modification, called the Syntetos-Boylan approximation (SBA) (Syntetos \& Boylan (2005)) which produces approximately unbiased forecasts. Teunter et al. (2011) proposed a method which updates forecasts at the end of every period (unlike Croston and SBA which update only after a demand occurrence).This is advantageous for supporting decisions on when to stop ordering items at risk of obsolescence.

Aside from these methods, there are also many other methods that have been used in forecasting intermittent spare parts demand, e.g. bootstrapping methods (see Willemain et al. (2004), and Viswanathan \& Zhou (2008)), support vector machines (see Hua \& Zhang (2006)), neural networks (see Gutierrez et al. (2008), Li \& Kuo (2008), Chen et al. (2010), Kourentzes (2013), and Wu et al. (2014)), and Bayesian approaches (see Yelland (2010)). Another notable paper by Romeijnders et al. (2012) proposed a two-step method. Different from traditional methods, the proposed two-step method uses time series data including spare parts consumption data and component repair data. A comparative study in the aviation industry showed that it can perform considerably better than Croston's method. The two-step method uses information on planned maintenance and repair operations to reduce forecast errors.

Comparison of forecasting methods: Many comparative studies, including empirical studies and simulation experiments, have been conducted in order to validate the above methods. Ghobbar \& Friend (2003), assessed the improvement in accuracy, using Mean Absolute Percentage Errors (MAPEs), of the following methods: weighted moving average (WMA), double exponential smoothing (DES) and CR compared with simple exponential smoothing (SES), additive Winters (AW), 
multiplicative Winters (MW), seasonal regression model (SRM), weighted calculation of demand rates (WCDR), weighted regression demand forecasters (WRDF), exponentially weighted moving average (EWMA), trend adjusted exponential smoothing (TAES), and adaptive-response-rate single exponential smoothing (ARRSES). Another empirical study by Regattieri et al. (2005) showed that the best approaches, according to the Mean Absolute Error (MAE), expressed as a ratio of average demand, are WMA, CR, and EWMA compared with SES, DES, TAES, MW, SRM, ARRSES, and moving average (MA). Eaves \& Kingsman (2004), Syntetos \& Boylan (2005, 2006), and Teunter \& Sani (2009) demonstrated the superiority of the SBA method compared to SES, CR, and MA. These papers used a variety of error metrics including Mean Error (ME), Mean Absolute Error (MAE), Root Mean Square Error (RMSE), and Relative Geometric Root Mean Square Error (RGRMSE). Two of the papers (Eaves \& Kingsman (2004) and Syntetos \& Boylan (2006)) went further and used inventory metrics to determine the effect of improved accuracy on stock performance. Teunter \& Duncan (2009) also carried out an empirical study, using inventory measures, and CR, SBA and bootstrapping clearly outperform MA and SES. Gutierrez et al. (2008) obtained very promising results for a neural network approach, showing improvement in accuracy over SES, CR and SBA using the metrics of MAPE, RGRMSE and Percentage Best (based on absolute errors). Kourentzes (2013) replicated the method of Gutierrez et al. (2008) and evaluated a new neural network method. The accuracy results, based on ME and MAE, showed little benefit in using neural networks over parametric methods, disagreeing with Gutierrez et al. (2008). However, better service level performance was obtained using neural networks, with little difference in stock-holding volumes. Compared with parametric methods, Zhou \& Viswanathan (2011) showed that a bootstrapping method performs better with randomly generated data sets, where there is a large amount of (simulated) historical data to generate the distribution. But, with real industry data sets, parametric methods seem to perform better than the bootstrapping method. Van Wingerden/et al. (2014) performed an empirical comparison of three different types of forecasting methods: i) traditional methods such as simple moving averages (SMA) and SES, ii) Croston's method and its various approximations, and iii) bootstrapping methods. Based on data provided by three companies, Van Wingerden et al. (2014) found that traditional methods performed worst for all three companies. Croston type of methods performed similarly with SBA the best. Bootstrapping methods performed best for two companies, especially for fill rates that were not too high, but badly for the third. Syntetos et al. (2015) analyzed two datasets, showing that simple parametric methods perform well, and it is questionable whether bootstrapping is worth the added complexity. 
Performance Metrics There is a growing body of evidence on the performance of various methods for forecasting intermittent demand, which is commonly observed for spare parts. A limitation of the research conducted so far is the lack of commonality of performance metrics. Some studies have not investigated inventory implications at all. This is unfortunate because it is possible for small improvements in accuracy to translate to more significant improvements in inventory performance. Turning to accuracy metrics, some of the measures used are inappropriate for intermittent demand. The Mean Absolute Percentage Error (MAPE) is undefined for zero observations and some authors have not specified how it is calculated for intermittent series. (An exception is the paper by Gutierrez et al. (2008) in which it is clarified that the MAPE is calculated as a ratio of the sum of absolute errors to the sum of demands, following Gilliland (2002)). The drawbacks of using the Mean Absolute Error were pointed out by Teunter \& Duncan (2009). These authors showed that the use of the Mean Absolute Error criterion can lead to a Zero Forecast method (always forecast zero) being the best performing method, although it is heavily biased. A similar limitation affects the Mean Absolute Scaled Error (MASE) proposed by Hyndman (2006) as an accuracy measure for intermittent demand. To address these shortcomings, measures of both bias (eg ME) and accuracy (eg MAE, MSE) are required in future studies, to complement inventory measures of achieved service levels and stock-holding volumes.

\subsection{Reliability based forecasting}

The most appropriate time-series based forecasting approach depends on the availability of historical data. In some cases, there is little time series data available to forecast the future demand. In such cases, practitioners can use reliability and maintenance variables to forecast spare parts demand, as long as these variables are known or may be estimated. These models may also prove beneficial when more extensive historical demand data are available, depending on their predictive strength.

Ghobbar and Friend (2002) examined the causal factors behind intermittence and lumpiness of demand for aircraft spare parts. They found evidence that the main factors were the aircraft utilization rate, the component's overhaul life, and the primary maintenance process. Ghobbar and Friend (2003) went on present a predictive error forecasting model, which compares forecasting methods based on their factor levels when demand is intermittent.

Ghodrati (2005) pointed out that the reliability characteristics of an existing machine or system are influenced not only by the operating time, but also by factors such as the environmental parameters (e.g. dust, humidity, temperature, moisture, etc.), which can degrade or improve the reliability. 
Therefore, a method was developed to forecast and estimate accurately the spare parts requirements considering the operating environment and to create rational part ordering strategies. Subsequent studies of the same topic (see Ghodrati and Kumar (2005), Ghodrati (2006), and Ghodrati et al. (2013)) showed that there is a significant difference in spare parts estimation when considering or ignoring the influence of the operating environment. Similarly, Barabadi (2012) presented a proportional hazard model and its extension in order to analyze the effect of the operational environment for spare parts provision. Later, Barabadi et al. (2014) applied reliability regression models with covariates for the provision of spare parts for drill bits. Tracht et al (2013) showed how condition monitoring data from a wind farm management system can be used to inform demand forecasting of spare parts.

Wang (2011) presented spare parts provision and planned maintenance as two related logistics activities, which must be considered together to achieve cost effective and efficient logistics support. He considered joint optimization of ordering quantity, ordering interval and inspection interval, using a Delay-Time (DT) concept (where the DT is the time from the initial) point of an identifiable defect to failure). Considering block inspection and age inspection policies, Wang \& Syntetos (2011) established a model of forecasting spare parts demand based on the delay-time concept. This research offered useful insights as to why the demand for spare parts is intermittent, as well as showing how to use models developed in maintenance research to facilitate the forecasting of intermittent demand.

Hua et al (2007) developed a method which forecasts the occurrence of non-zero demand using explanatory variables using a logistic/regression approach. The explanatory variables may be categorical (eg plant and overhaul equipment arrangements). Romeijnders et al (2012) take a different approach, starting at the component level. For each type of component, the number of repairs and the average demand per repair are estimated. Then, by combining the demand forecasts over all relevant components, a spare/part demand forecast is obtained. The new method shows considerable promise, having outperformed time-series forecasting methods in a case study at Fokker Services.

\subsection{Judgmentally based forecasting}

There is some element of judgment in almost all forecasting processes. In some cases, a forecast may be purely judgmental. For example, for new products, it may not be possible to generate a statistical forecast because of the lack of historical data on sales. In other cases, a statistical forecast may be produced, but is then amended by a demand planner in the light of the planner's judgment about changes in the internal or external environments.

There is little empirical evidence on the accuracy of judgmental adjustments to statistical forecasts, 
and even less on the slow moving items typically observed in a maintenance context. Fildes et al. (2009) analyzed the demand forecasts, at SKU level, from four companies, who had kept records of both their statistical and adjusted forecasts. They found that positive judgmental adjustments, which increase a statistical forecast, offer a lower improvement in accuracy than negative adjustments. For both positive and negative adjustments, forecast improvement increases with the size of the adjustment (as a proportion of the statistical forecast). A parallel study was conducted by Syntetos et al. (2009b) which focused on intermittent demand items from one of the companies analyzed by Fildes et al. (2009). Judgmental adjustments were found to be common, with $74 \%$ of forecasts being adjusted. The results showed that: i) overall, there is an improvement in accuracy from judgmental adjustments; ii) negative adjustments perform better than positive adjustments; iii) positive adjustments perform rather poorly, irrespective of their magnitude; and iv) small positive adjustments (less than 20 units) improve the accuracy of zero forecasts. Syntetos et al. (2009b) also showed that the improved accuracy of the judgmentally-adjusted forecasts was translated into better inventory service level performance. However, these results are based on evidence from just one pharmaceutical company and more studies are needed to give greater confidence in, or to challenge, the four conclusions given above.

\subsection{Remarks}

Time-series, reliability and judgmentally based forecasting are complementary approaches, whose scope for application largely depends on the availability of demand data and data on causal variables. Based on the previous discussion, we can summarize the main issues as follows:

Firstly, regarding time-series based forecasting, three approaches have been suggested: i) parametric, ii) neural networks and iii) bootstrapping. The literature on parametric methods is the most extensive, and contains evidence that bias-corrected methods may improve accuracy and inventory performance, when compared to more traditional methods. However, some studies have used inappropriate error metrics and there has been a lack of consistency in the use of such metrics, making it difficult to compare the results in different papers. The literature on neural networks and bootstrapping is more sparse, with inconclusive empirical evidence thus far. The whole area would seem to merit further research, using more appropriate and consistent metrics, taking into account both accuracy and stock-control performance. For intermittent demand, accuracy evaluation, particularly when based on absolute-error metrics, should be combined with bias evaluation. This safeguards against misleading findings and any reductions in over-forecasting will result in inventory savings.

Secondly, more and more contributions consider complex situations, including the influence of the 
operating environment and different maintenance strategies when developing reliability based forecasting models. However, we found only three papers (Ghobbar \& Friend (2003), Wang \& Syntetos (2011), Romeijnders et al. (2012)) containing comparative studies between time-series based and reliability based demand forecast approaches. Based on these comparative studies, it is inconclusive to decide which approach is better. There may be conditions under which one approach is preferred to the other; more research is certainly needed to understand what these conditions are. A further promising research area might be to provide a mechanism to combine the strengths of both time-series and reliability based forecasts. The simplest way of doing this is to calculate an averáge (or weighted average) of the two forecasts; more complex models may involve both auto-regressive and regressive components.

Thirdly, there has been some recent interest in judgmental forecasting. However there is limited empirical evidence on its accuracy when compared to time series methods and no evidence when compared with reliability based methods. The limited number of studies to date demonstrates the potential accuracy gain by the use of judgment, but also point to some of the limitations of judgmental methods. More evidence, particularly on the occasions when judgment may improve statistical forecasts, would be very welcome. From a practical perspective, companies would be well advised to keep records of both their statistical and judgmentally adjusted forecasts. This will enable them to assess the gains or losses in forecast accuracy from the use of judgment, and to identify the circumstances when there is most benefit from judgmental adjustment.

\section{Optimization}

One of the biggest challenges in inventory management is to achieve high system availability with minimal inventory. That is why researchers have been seeking effective ways to achieve inventory optimization for decades. There have been several literature reviews (Kennedy et al. (2002), Paterson et al. (2011), Bakker et al. (2012), Guide \& Srivastava (1997), Basten \& Van Houtum (2014), Van Horenbeek et al. (2013)) related to this issue, adopting a variety of perspectives. Kennedy et al. (2002) review contributions on multi-echelon problems, and repairable spare parts. Paterson et al. (2011) review contributions related to inventory models with lateral transshipments; Bakker et al. (2012) carry out a literature review of papers since 2001 on inventory systems with deterioration; Guide \& Srivastava (1997) focus on repairable inventory theory; Basten \& Van Houtum (2014) review contributions about system-oriented inventory models for spare parts, including single location models, multi-echelon models, lateral and emergency shipments, and other extensions such as condemnation, 
repair shop capacity planning, and level of repair analysis; and Van Horenbeek et al. (2013) review contributions related to joint maintenance and inventory optimization systems. In this paper, we conduct a review of spare parts optimization from a different perspective, focusing on the product life cycle process for spare parts. In doing so, we divide the relevant contributions into three groups, namely i) optimization of system parameters, ii) optimization of replenishment quantities, and iii) end-of-life orders and reuse supply chain design.

\subsection{Optimization of system parameters}

When new equipment is introduced, a spare parts replenishment system needs to be established to effectively provide spares supply support. When the inventory system for each group of spare parts is determined, optimization is required to further calculate the best system parameters. Normally one would expect an initial phase of design as a pre-life phase that extends the product life cycle framework. Accordingly, we provide the design phase in our extended framework for OR in spare parts management in Figure 2 in Section 8 of this paper. There is very limited research on this emerging research direction. Öner et al. (2010) investigated the reliability of the critical components at a system level (measured as function of MTBF) during the design phase of a capital good. They showed that the value of MTBF of a component is dependent on whether the component is cheap or expensive, the number of systems to be installed, the downtime penalty rate and the length of exploitation phase. This emerging idea of considering the design phase of the capital equipment has also been investigated by Smets et al. (2012), where they proposed a framework of 'design for availability' aiming to help manufacturers of capital goods and their customers to cost-effectively produce and use capital goods that meet high system availability requirements. By introducing the pre-life phase in the extended framework, we encourage more attention and efforts in this area.

During the initial period, spare parts managers have two main choices to satisfy the needs for new equipment maihtenance: stock initial spare parts, or place an order when demand takes place. Procurement of initial spare parts is common practice. The system approach can be used for initial provisioning as well as follow-on spares support (Guide \& Srivastava (1997) and Eren \& Erol (2015)). Since several contributions (Kennedy et al. (2002), Paterson et al. (2011), Bakker et al. (2012), Guide \& Srivastava (1997), Basten \& Van Houtum (2014)) include a literature review of the system approach, in this review there is no need to repeat this work.

In addition to the technical problems of initial provisioning, there are also some practical problems that have been considered. For example, Schweitzer (1967) and Jaquette \& Osaki (1972) developed 
methods of initial provisioning considering spare parts deterioration; Burton \& Jaquette (1973) and Pérès \& Grenouilleau (2002) considered the problem of spare parts optimization under a limited procurement budget constraint; Walker (1996), Fortuin (1984), and Haneveld \& Teunter (1997) considered the problems of initial supply and ordering strategy jointly; Burton \& Jaquette (1973), Walker (1996), and Haneveld \& Teunter (1997) studied the initial provisioning for insurance type spares or expensive slow-moving parts. Although there is a lack of consumption data of spare parts when new equipment is introduced, there is a lot of equipment design data, which can be used for initial provisioning. Van Jaarsveld \& Dekker (2011) proposed using the data gathered in reliability centred maintenance (RCM) studies to determine shortage costs when determining how many spare parts to stock. An approximative analytic method was developed to determine minimum stock quantities in the case of redundancy and multiple systems.

Kader et al. (2015) proposed an aggregated optimal production and maintenance plan over a finite horizon, which minimizes the global cost including production costs, maintenance interventions and spare parts costs and the carbon footprint. In order to minimize the carbon footprint, the possibility of maintaining equipment with used spare parts was added, and it brought many advantages such as bulk buying (without packaging), less cost, and less impact on the environment; and different mathematical models were used so as to reduce carbon rejections during deliveries and storages (ecological order quantity). This is one of the few papers to consider environmental objectives in spare parts optimization.

\subsection{Optimization of replenishment quantities}

After the initial provisioning phase in connection with procurement of new equipment, then spares supply support goes into a normal operation phase. The main task of spares supply support in this phase is to continuously replenish spare parts to fulfill maintenance needs based on the real consumption data of spares. There are four standard stocking policies commonly used in spare parts management: i) continuous review, with fixed reorder point $(r)$ and fixed order quantity $(Q)$, referred to as $(Q, r)$; ii) continuous review, with fixed re-order point $(s)$ and order-up-to level $(S)$, referred to as $(s, S)$; iii) periodic review, with fixed ordering interval $(T)$ and order-up-to level $(R)$, referred to as $(T$, $R$ ); and iv) continuous review and order-up-to level $(S)$ in a one-for-one replenishment mode, referred to as $(S-1, S)$.

Most research papers focus on stocking policies in order to supply production lines with material, and stock control for distribution networks (Fortuin \& Martin (1999)). Here we discuss another two 
critical issues when making decisions on replenishment, namely: i) how to link replenishment to forecasting? ii) how to replenish spare parts under some constraints? The first issue is central to spare parts management but our review has found relatively few papers dedicated to the subject.

Inventory replenishment based on forecasting: For $(r, Q)$ and $(S-1, S)$ policies, once the parameters $r, Q$, and $S$ are determined, the replenishment issue (order quantity) is also determined. By contrast, for the $(s, S)$ and $(T, R)$ policies, the order quantity depends on the 'real-time' forecasted demand over the lead time and next review cycle. Different forecasting methods have been reviewed in Section 4. However, most of the reviewed contributions concentrated on developing new forecasting methods and evaluating forecast accuracy, and very few of them linked forecasting to stock control. Eaves \& Kingsman (2004) integrated demand pattern classification, demand forecasting, and forecasting performance evaluation, and showed that the methodology presented could be extended to assist with the setting of safety stock levels for operational purposes. Syntetos \& Boylan (2006) examined the stock control implications of alternative intermittent demand estimators in conjunction with a periodic order-up-to level $(T, R)$ model, and comparative results demonstrated the superior stock control performance of the SBA method. Viswanathan \& Zhou (2008) and Zhou \& Viswanathan (2011) developed a new bootstrapping method to calculate optimal order-up-to-levels based on the required cycle service level. Teunter \& Duncan (2009) carried out a comparative study to evaluate performance of different forecasting methods focusing on an order-up-to policy in an inventory system with backordering. Based on the study results, they suggested a modification to the determination of order-up-to levels by taking into account that an order in a period is triggered by a demand in that period, and it was shown that the modification significantly improves the performance of Croston's, SBA and bootstrap methods.

Inventory replenishment considering some special cases: In order to reduce modeling complexity, many inventory models have been developed under some simplifying assumptions. Nevertheless, some authors have relaxed these assumptions to address real world complexities. We discuss four such complex situations below highlighting, in particular, the modest literature on the important topic of service targets at higher levels than the individual part.

i) Inventory replenishment considering finite repair capacity constraint. Most of the traditional inventory control models are based on the assumption of ample repair capacity, which can introduce a serious underestimation of the spare parts requirements in systems with high repair facility utilization (Diaz \& Fu (1997)). Several contributions (Costantino et al. (2013), Diaz \& 
Fu (1997), Sleptchenko et al. (2002, 2005), Lau \& Song (2004, 2008)) carried out studies of how finite repair capacity affects inventory systems, and developed models for multi-echelon repairable item inventory systems with limited repair capacity to reduce stock investment. The relevant studies showed that the proposed models in the case of limited repair capacity significantly outperform traditional models, such as METRIC and VARI-METRIC. Different from the above contributions, there are also several studies concerning problems of finite repair capacity, which address the joint optimization of spare parts and repair capacity. Sleptchenko et al. (2003) and Buyukkaramikli et al. (2015) developed models for joint optimization of inventory levels and repair capacity. de Smidt-Destombes et al. (2004, 2006, 2007, 2009) conducted joint optimization of the spare part stock level, the maintenance policy and the repair capacity for $k$-out-of- $N$ systems. Rappold \& Van Roo (2009) proposed/an approach to model and solve the joint problem of facility location, inventory allocation and capacity investment. Jin et al. (2015) proposed a game-theoretical approach to jointly optimise the maintenance, the spares inventory, and the repair capacity.

ii) Inventory replenishment considering time-varying demand. In a realistic product life cycle, demand is increasing with time during the growth phase; after reaching its peak, the demand becomes stable for a finite time period called the maturity phase; and then the demand starts decreasing with time and eventually reaches zero (see, for example, Hariga (1996)). With respect to this kind of time varying demand, demands for spare parts of new equipment increase very rapidly while the demands for spares of the obsolete equipment decrease very rapidly with time. There are many contributions, such as Khanra et al. (2011) (2013), Jin \& Liao (2009) and Jin \& Tian (2012), which have developed order-level inventory models for this situation. Aside from this factor, there are also some other special factors causing time-varying demand for spare parts: Jung (1993) presented a methodology for a recoverable inventory system under reliability improvement, which can result in time-varying demand; Lau et al. (2006) developed a model to compute time-varying availability, caused by the variation of equipment utilization rate over time, for repairable item inventory.

iii) Service targets at higher levels than the individual part. A number of authors have addressed the problem of optimizing inventory levels when service is measured at a higher level than that of the parts themselves. There are two principal applications that have been researched: i) inventory systems designed to ensure that turn-round times are attained for a whole repair 
component (which may require many parts; ii) the 'repair kit' of a set of parts which a repairman(woman) is supplied to conduct a number of repair jobs. In both cases, the aim is to achieve better alignment of inventory models with business objectives.

Kumar and Knezevic (1998) proposed a mathematical programming model to maximize the availability of a component requiring a number of spares, subject to cost and weight constraints. Sudiarso and Labib (2002) developed a rule-based fuzzy logic system to translate the frequency of machine breakdown, and the number of similar parts required in each breakdown, to the part arrival rate. Teunter (2006) examined the repair kit problem, motivated by a real-life setting of repairs for photocopiers. He examined heuristics based on the 'job fill rate' and the 'part fill rate' (fraction of parts that are not missing for a job) and found that the Part Heuristic performed almost as well as the more complex Job Heuristic. Bijvank et al. (2010) extended Teunter's model by introducing an exact formulation for the service level and introducing an algorithm including the new service level formulation. Mirzahosseinian and Piplani (2011) modeled the interaction among the base stock level at the warehouse, component reliability (Mean Time Between Failures), the efficiency of the repair facility (Mean Time To Replace) and the availability of the entire set of systems. Van Jaarsveld et al. (2015) developed a model based on the requirements of Fokker Services. In this model, targets are set at the level of components rather than at the level of spare parts. Given the importance of the issue, these recent advances are welcome, although the volume of research remains modest.

iv) Inventory replenishment considering environmental issues. As stated above, considering environmental issues in spare parts optimization is an emerging research topic. The contributions with respect to spare parts replenishment considering environmental factors, to the best of our knowledge, are rare. Digiesi et al. (2015) extended the economic order quantity (EOQ) model by considering a new cost function that includes both economic and environmental costs relating to repair and replacement, including the environmental cost of the production of new parts and the disposal of used parts. The new cost function made it possible to solve the single-product replenishment problem of repairable spare parts under uncertain and stochastic demand, providing solutions consistent with both economic and environmental goals. The improved EOQ model took into account both the repair cost and the purchase cost of a new spare part if the failed part cannot be repaired. The optimal means of transport and the corresponding sustainable EOQ value, as well as the optimal repair policy, were identified. 


\subsection{End-of-life orders and reuse supply chain design}

The end-of-life (EOL) phase is the final phase of the product life cycle and begins when the product is taken out of production and ends when all service contracts have expired (Teunter \& Fortuin (1998)). The end-of-life inventory problem is also called the final buy problem, the all-time buy problem, and spare parts procurement after end-of-production. In order to reduce end-of-life orders, researchers and practitioners have considered recycling the obsolescent equipment as the source of spare parts. This strategy can not only reduce end-of-life orders and make full use of the residual value of obsolescent equipment to the extent, but also reduce environmental pollution. So, end-of-life orders and reuse supply chain design should be jointly considered. In this section, the contributions $/$ concerning end-of-life orders and reuse supply chain design in spare parts management are reviewed together.

Calculating final order size: To the best of our knowledge, Fortuin (1980) developed the first model to calculate the final order size for given service levels. His model assumed exponentially decreasing demand during the EOL and a Gaussian demand distribution. This was then extended by Fortuin (1981), in which the minimum service level requirement is reduced to only the first few years of the post-manufacture period. Teunter \& Fortuin (1998, 1999) and Teunter \& Haneveld (1998) developed cost-driven approaches from sellers' and buyers' perspectives respectively to calculate the optimal final order size. Van Kooten \& Tan (2009) established the first model for calculating the final order size for repairable spare parts considering a predefined service level and explicitly taking condemnation into account.

End-of-life inventory control: The traditional mechanism of spare parts acquisition is to place a large final order at the end of regular production of the parent product, causing major holding costs and a high level of obsolescence risk (Inderfurth \& Kleber (2013)). In addition to the final order quantity, flexible inventory control policies should be considered when making decisions on end-of-life invehtory. Teunter \& Haneveld (2002a, 2002b) proposed a new ordering policy consisting of an initial order-up-to level at time zero, and a subsequent series of decreasing order-up-to levels for various intervals of the planning horizon, and developed cost-driven methods to calculate the optimal policy for a single-echelon inventory system and a two-echelon inventory system respectively. Pourakbar \& Dekker (2012) addressed the inventory control problem in the end-of-life phase by considering customer differentiation for both demand criticality and service contracts, and showed that inventories should be optimally controlled according to threshold levels that consider both remaining time to the end of the horizon and the level of serviceable inventory. Later, Pourakbar et al. (2012) 
considered that there might be a point in time at which the unit price of the product is lower than repair associated costs because the unit price will decrease with time, and then proposed new policies to simultaneously find the optimal final order quantity and the time to switch from the repair to an alternative replacement policy.

Reuse supply chain design: A range of recovery options, including refurbishing, remanufacturing, and recycling, may allow companies to recapture part of the original value added or the value of materials, thereby increasing their profits (Thierry et al. (1995) and Fleischmann et al. (2003)). This provides another option for considering environmental problems in spare parts management, namely combining spare parts management and reverse logistics. Several contributions (Fleischmann et al. (2003), Inderfurth \& Mukherjee (2008), Spengler \& Schröter (2003), Schröter \& Spengler (2005), Krikke \& Van Der Laan (2011), Kleber et al. (2012), Pourakbar et al. (2014) and Behfard et al. (2015)) explored the end-of-life inventory problem by taking into account product returns as a source of spare parts. Fleischmann et al. (2003) pointed out that IBM was among the pioneers recognizing the benefits of closed-loop supply chains that integrate product returns into business operations, and exploiting product returns as a source of spare parts. Inderfurth \& Mukherjee (2008) considered three procurement options for spare parts in post product/life cycle, namely remanufacturing of used products and components, a final lot at the end of the regular production cycle, and setting up extra production lots until the end of service. Decision trees and stochastic dynamic programming were applied to determine the optimal combination of these three options. Later, Inderfurth \& Kleber (2013) developed a simple order-up-to decision rule based on advanced heuristics for joint production and remanufacturing, which was claimed to be very effective and practical. Spengler \& Schröter (2003), Schröter \& Spengler (2005), Krikke \& Van Der Laan (2011), Kleber et al. (2012), Pourakbar et al. (2014) and Behfard et al. (2015) combined spare parts management and reverse logistics. The methods of spare parts inventory planning in the final phase were developed by taking into account the recovered components from discarded equipment, the repair of failed products, and the cannibalization of system phase-outs.

\subsection{Remarks}

There are different concerns for spare parts management in different stages of the equipment lifecycle process. By taking into account the specific characteristics of spare parts demand for each phase of spare parts control, it is easier to adopt different measures to achieve highly effective spare parts control. For example, in the equipment procurement phase, there is a copious amount of system 
design data which can be taken full advantage of when planning spare parts supply system for new equipment to improve its availability and reduce investment on spares; in the normal phase, there are sufficient spare parts consumption data to allow time-series forecasting methods to be adopted for spare parts control; while remanufacturing of used products and components can be adopted in the end-of-life phase. There have been some welcome developments in modeling the interaction between forecasting and inventory replenishment. The nature of spare parts demand, which is often intermittent, has been taken into account, providing workable models for practical implementation. The developments in optimization models at levels higher than the individual part are also welcome, especially as some of these models have already been implemented in commercial organizations.

The importance of environmental issues is being recognized more widely across many sectors of the economy. More and more institutions are using green facilities and equipment to respond to the regulations of carbon emissions and environmental protections. From the view of operations management, reduction of carbon emissions can be achieved by means of optimizing operations of production, transportation and inventory. In recent years, researchers have begun to model environmental issues in general inventory control through introducing environmental constraints such as an emission capacity constraint (Helmrich et al. (2015)); or employing multiple objectives, such as integrating sustainable development criteria into inventory models (Bouchery et al. (2012)). Compared to general inventory control, environmental issues have been seldom addressed in the contributions of spare parts control. Only two contributions (Digiesi et al. (2015) and Kader et al. (2015)) directly included environmental problems in their proposed optimization models. However, several other contributions (Fleischmann et al. (2003), Inderfurth \& Mukherjee (2008), Spengler \& Schröter (2003), Schröter \& Spengler (2005), Krikke \& Van Der Laan (2011), Kleber et al. (2012), Pourakbar et al. (2014) and Behfard et al. (2015)) 'indirectly' considered environmental protection problems in their optimization models, which combined spare parts management and reverse logistics, such as remanufacturing of used products and components, the repair of failed products, recovering components from discarded equipment, and the cannibalization of system phase-outs. In the future, much more emphasis should be placed on environmental problems in spare parts management.

\section{Simulation}

In the past few decades, simulation has been recognized as a very useful technique in the field of operations management and modeling (Amoako-Gyampah \& Meredith (1989), Pannirselvam et al. (1999), and Jahangirian et al. (2010)). Early work tended to focus on queuing models for spares 
management (eg Mani \& Sarma (1984), Gross et al (1985)) but queuing models tend to become intractable as the problem structure becomes more complex. Because of the advantages of simulation in solving complex problems, it has been widely used in spare parts management. Based on the purpose of simulation in spare parts management, we classify the related research into two groups, assessing alternative designs and simulation of system parameters.

\subsection{Simulation of alternative designs}

In order to ensure that the designed inventory system is the most appropriate one, practitioners always need to further evaluate potential designs before implementation, giving them confidence in putting any change into practice. This is essential in cases where it is very costly to make subsequent changes at later phases within the process life cycle, such as in the aircraft industry. Simulation is a very powerful tool to assess alternative designs. Even if simulation gives analysts negative assessment results, they can use simulation to further analyze the weakness of the given inventory system, and then improve it.

System dynamics is an established method of solving dynamic, complex, and ill-structured decision problems (Sterman (2000)). Spengler \& Schröter (2003) used system dynamics to model an integrated production and recovery system for supplying spare parts to evaluate possible strategies for meeting spare parts demand for electronic equipment in the end-of-life service period. Schröter \& Spengler (2005) developed a system dynamics model to test various policies (such as when to stop sending recoverable parts to materials recycling, when to acquire units of equipment with recoverable parts and when to begin to redesign a spare part) to control closed-loop supply chains with parts recovery and spare-parts supply. Kumar \& Vrat (1994) synthesized physical system theory and system dynamics to model and study the dynamics of multi-echelon, multi-indentured repair inventory systems. Tian \& Zhao (2009) applied system dynamics theory to analyze the supply of flow of spares parts and to optimize a support strategy for 'high efficiency and low cost'. Song \& Yang (2015) used system dynamics to analyze the warship support problem under two types of strategies, namely lateral transshipment supply and cannibalization. It was shown that combining the lateral supply and cannibalization strategies can reduce the inventory of warships carrying spare parts.

Compared to system dynamics, discrete event simulation and Monte Carlo simulation have more applications in stocking policy modeling. Duffuaa et al. (2001) developed a generic conceptual simulation model for maintenance systems, which can be used to study manpower requirements, spare parts provisioning and the impact of various priorities adopted by maintenance management. The 
model can evaluate the need for contract maintenance and the impact of spare parts availability on various measures of performance. Pall (2008) proposed a discrete-event simulation model to evaluate aircraft availability at any given time during a simulation run, assuming an ideal sparing situation, and showed that the fleet's availability cannot be solved simply by addressing the logistical problem of the spares. Rossetti \& Thomas (2006) presented a standardized, object-oriented, data-driven, simulation framework for evaluating a multi-echelon multi-indenture spare parts supply chain network. Persson \& Saccani $(2007,2009)$ developed a model using discrete event simulation to evaluate spare parts inventory and distribution systems and to analyze the spare parts classification criteria, which led to the definition of inventory policy. Zhao et al. (2015) presented a simulation framework to evaluate spares supportability, considering the complex conditions including product multi-failure modes, preventive maintenance, non-exponential distributions of spares demand, multi-echelon inventory system and lateral transshipments.

\subsection{Simulation of system parameters}

Analytic models are sometimes preferred in practice because they are easy to use, whereas developing simulation models is time-consuming and costly. Nevertheless, developing analytic models for complex situations require assumptions to simplify the modeling. This sometimes makes the models unrepresentative of the real world, affecting their application. In this case, developing simulation models may be preferred.

Simulation of inventory policies: If the joint optimization of maintenance and spare parts is very complicated, then simulation modeling may be of value. Kabir \& Farrash (1996) developed simulation models to jointly optimize age-based preventive maintenance and a continuous review inventory policy $(s, S)$. Sarker \& Haque (2000) developed a simulation model for a system operating with block replacement and a continuous review inventory policy $(s, S)$. Wang et al. (2009) developed a Monte Carlo simulation model for the operation of an inventory system under condition-based replacement and spare provisioning policy ( $T, S, s, L_{p}$ ), where $T$ is the inspection interval, $S$ is the maximum stock level, $s$ is the reorder level, and $L_{p}$ is the preventive replacement threshold for the deterioration levels of units. Different from these research papers, Tiacci \& Saetta (2011) examined lateral shipments to reduce the mean supply delay of a non-repairable item by means of developing a simulation model of a two echelon supply network. Van Jaarsveld \& Scheller-Wolf (2015) developed an algorithm and used simulation to optimize base-stock levels within the class of independent base-stock replenishment policies, for First-come-first-serve (FCFS) systems consisting of hundreds of components. It was also 
applied on spare parts optimization tasks for a real repair shop owned by Fokker Services (Van Jaarsveld et al. 2015).

Through developing simulation models, it makes it easy to solve complicated inventory problems under complex maintenance strategies (such as condition based maintenance) and advanced inventory policies (such as lateral shipment).

Simulation of stock size: A drawback of the VARI-METRIC models developed so far is the fact that they are static in nature, i.e. they assume stationary stochastic failure, no condemnation (items can always be repaired), and system structure which never changes. Unfortunately, such assumptions are seldom realistic (Rustenburg et al. (2001)). In recent years, simulation optimization has received considerable attention from both simulation researchers and practitioners. Because of the complex situations commonly encountered in spare parts management, simulation optimization is a very promising method to cope with such critical issues as spare parts allocation. Marseguerra et al. (2005) proposed an approach to the multi-objective Pareto optimization of spare parts allocation based on a combination of genetic algorithms and Monte Carlo simulation. The modeling of the system failure, repair and replacement stochastic processes was done by means of Monte Carlo simulation. Dubi (2006) integrated a Monte Carlo method and marginal analysis to optimize spare parts in complex realistic scenarios. Lee et al. (2008) developed a multi-objective simulation optimization framework, which integrates simulation, a multi-objective evolutionary algorithm and a multi-objective computing budget allocation method, for the aireraft spare parts allocation problem to provide a non-dominated Pareto set of solutions to the decision makers. Therefore, although a simulation method cannot be directly used to optimize a system by itself, it has been coupled with optimization algorithms to solve optimization problems.

\subsection{Remarks}

From the above review, we can see that simulation has been widely used for optimization, evaluation, and testing in the research of spare parts management. In most cases, the problems addressed are complex situations in spare parts management, such as multi-echelon, multi-indenture spares optimization under not-constant failure rate distributions, lateral transshipment supply, and product multi-failure modes. Especially for those systems with time-varying usage rates, spare parts management is a challenging task for practitioners without an effective simulation tool. Therefore, with a growing need to address the complexities of spare parts supply systems, it is becoming increasingly difficult to develop analytic models to solve such problems, and simulation is a powerful 
technique of solving complex problems in spare parts management.

Many research papers reviewed in previous sections used simulation to validate their proposed analytic models. For instance, simulation has been used to validate the models of spare parts classification proposed by Syntetos et al. (2005), Syntetos et al. (2012), and Bacchetti et al. (2013); verify the demand forecast models proposed by Syntetos \& Boylan (2001) and Wang \& Syntetos (2011); and verify the stock optimization methods developed by Van Jaarsveld \& Dekker (2011), Rappold \& Van Roo (2009), and Jin \& Liao (2009). Therefore, simulation can be used to test how well the analytic models work. If analytic models are verified to be effective in solving problems through simulation based on real-world data, then practitioners may use them with confídence, removing the need for repeated use of simulation models. In situations where companies are initially unwilling to disclose data, simulations may be conducted using synthetic data first. Ayiomamitou (2016) gives an example of this in the third party logistics sector. When confidence had been gained in the potential benefit of a new inventory dispositioning model, the company was more willing to make their data available for more rigorous model testing, eventually leading to full model implementation.

So, simulation is continuing to be an important and effective enabling technology to validate the analytical models and methods proposed by many researchers. Other research papers synthetically used simulation and analytic methods to solve the problem of multi-objective spare parts optimization. Nevertheless, the relevant research concerning this topic, to the best of our knowledge, is rare. More research work on the topic of spare parts simulation optimization should be conducted in order to investigate how complex situations affect spares stock.

\section{Applications of the Theory}

From the previous sections, we can see that there have been major advances in addressing the problem of spare parts management, and we can also appreciate some specific applications in certain fields through case studies. In a recent review of system-oriented models for spare parts, Basten \& Van Houtum (2014) provide an overview of models which have been implemented in software tools (e.g. VARI-METRIC, MOD-METRIC, OPUS10, Optimizer, and GPS). While such successful model implementations are welcome, it must be acknowledged that many models have not been implemented in commercial software. In this section of the paper, we shall take a different perspective from Basten \& Van Houtum (2014), identifying some of the major challenges that still need to be addressed for models to be implement in software in a coherent way, reflecting our earlier discussions.

In many organizations, commercial software is supplemented by in-house developments. Our 
collective experience is that simple software or EXCEL tools are often developed by company employees. For these tools to be beneficial, developers need to have a good appreciation of the models available, and of their relative advantages and disadvantages. This appreciation may be facilitated by university and college courses including recent developments in OR models and by the encouragement of model evaluation skills. Such evaluation skills may be included by company-based projects where students learn about the practicalities, as well as the theory, of successful model implementation. In a fast-moving field, it is also important that training courses are available for employees to update their knowledge. For these courses to be useful, they need to be pitched at the right level and to coyer such issues as data requirements, data cleaning, parameter estimation and monitoring of results.

Returning to commercial software, the size of this market is difficult to assess due to lack of information in the literature. In 2005, the total market size of service parts management was estimated at $\$ 100$ million by Aberdeen Research. Since that time, our understanding is that companies have increased investments in spare parts management software applications, especially when embedded in Enterprise Resource Planning (ERP) packages. In the past few decades, many software packages have been developed to enhance the practice of spare parts management, and have achieved great success in some fields of industry as well as in the military. Nevertheless, some major problems remain.

Firstly, there is a lack of an integrated platform of spare parts management decision-making. An integrated platform here means: i) having multi-functions, including spare parts classification, demand forecasting, inventory optimization, and supply chain system simulation; ii) being designed for multi-phase use in the product lifecycle process. Unfortunately, many software packages were designed without considering the needs of spare parts management from a product lifecycle process perspective. Although each functional software package may have its own characteristics and superiorities in solving specific problems, it is obvious that an overall solution is needed in spare parts management. Some important functions, such as classification of spare parts demand patterns, joint optimization of maintenance and stocking policies, and end-of-life inventory decision-making are absent from most commercial software packages. In addition, many software packages are excessively self-contained. In most cases, it is very hard to exchange data with each other, and even harder to exchange data with other professional software, such as reliability, maintainability \& supportability (RMS) related software, and maintenance planning \& scheduling software, which can provide valuable information for spare parts management.

Secondly, many software packages for spare parts management decision-making run without 
making full use of the data from maintenance management information systems (MMIS), sometimes also called computerized maintenance management systems (CMMS). Moreover, such software packages tend to be used internally within the organization and there is no established business model in terms of feeding back such captured data about equipment failures to the designer or vendor of the equipment, which could have been helpful for design improvement decisions; see Labib $(1998,2003)$ for criticism of CMMSs. Jardine et al (2006) also commented that advanced maintenance technologies have not been well implemented in industry.

As mentioned above, Wang (2011) pointed out that spare parts provision and planned maintenance are two related logistics activities where maintenance generates the need for spare parts. In order to determine suitable spare part inventory levels, one must know about maintenance schedules and parts forecasting that feed into the material requirements planning (MRP) system (Ghobbar \& Friend (2003)). Nevertheless, spare parts are often managed through an inventory management system that relies on past spare part demands regardless of the maintenance process (Ghobbar \& Friend (2003), Wang (2011), Marseguerra et al. (2005), and Foote (1995)). However there are some packages that take this into account. For example, the team at the C-MORE Lab at the University of Toronto developed spare parts software called Spares Management Software (SMS) for spare parts optimization, where it calculates the recommended minimum number of spare parts in stock for the required reliability and given planning horizon (C-MORE, 2013; Ghodrati et al. 2012; and Jardine and Tsang, 2013). So, the SMS provides an analytical solution to the spare parts problem when there is no shelf-life effect, and can optimise for various factors (repairable vs. non-repairable, planning horizons, interval reliability levels etc.). SMS, however, does not have the capacity to account for degradation of spare parts on the shelf (Montgomery et al, 2014). This problem has stimulated some research. For example, Romeijnders et al. (2012), reviewed earlier, developed a two-step method of forecasting spare parts demand using component repairs information, and showed the superiority of using maintenance information in forecasting spare parts demand. More importantly, it is widely accepted that one of the potential benefits of condition-based maintenance (CBM) is the expected decrease in inventory as the procurement of parts can be triggered by the identification of a potential failure (Louit et al. (2011)). With the rapid progress of microelectronics and fault diagnosis, more and more embedded monitoring systems are used to continuously monitor the status of machinery and manufacturing devices, which allows users to identify degradation trends of the monitoring object, and then conduct failure prediction and CBM. Regarding this matter, Frazzon et al. (2014) took advantage 
of technical condition information from intelligent maintenance systems to improve operational planning of spare parts supply chains. Therefore, how to make full use of maintenance management information, especially CBM information, and interface design with MMIS in use need to be considered in the development of new generation software packages of spare parts management decision-making.

Last but not least, most software packages are still using traditional forecasting and inventory management techniques. More recently developed methods, especially those that have been empirically validated, need to be introduced into software packages. Regarding classification, for example, methods such as the Dominance-Based Rough Set Approach (DRSA) have the potential to be embedded in software applications. From a forecasting perspective, exponential smoothing and Croston's method are commonly employed, neglecting the methods reviewed in/Section 4 of this paper. Moreover, the most basic inventory theory and models (such as EOQ, ROP, ABC-analysis, MRP) have been widely applied, in practice, but there is relatively little evidence of the use of more sophisticated applications (Huiskonen (2001)). In the past decades, a large number of new models and techniques for different complex situations of spare parts management have been developed, many of which have not been implemented in commercial software.

Boylan and Syntetos (2016) suggested that there are three reasons for slow uptake of new models. Firstly, there is a knowledge gap. Practitioners do not always know what to ask for, especially if they have little knowledge of recent modeling developments. Secondly, there is a research gap. There are areas of importance to practitioners which are either neglected by researchers or have been inadequately researched from an empirical perspective. This means that software providers do not always have at their disposal methods that are known to perform well in a real-world setting. Thirdly, there is an implementation gap. Even when models have been empirically tested and found to be robust, software providers are often slow to incorporate these developments in their software. To bridge these gaps, closer collaboration is needed between researchers, practitioners and software providers. This collaboration may take a number of forms. Academics should include recent OR model developments in their teaching and training of students and practitioners, and to develop skills of model evaluation. Practitioners should be willing to make real-world data available to academics, thereby enabling new models to be tested and improved. Software companies should consider working collaboratively with researchers to move commercial software forward and make it more up-to-date.

\section{Conclusions}


The research scope of spare parts management is very wide. In this paper, we have provided a systematic review of OR in spare parts management. From a product lifecycle process perspective, we presented a new framework for OR in spare parts management, which is based on the classification of OR disciplines for supporting spare parts management. Then, 222 contributions have been systematically reviewed and organized according to the categories of spare parts classification, demand forecasting, optimization, and supply chain system simulation. Specific issues have been identified for each of these categories, which will not be repeated here. Instead, we revisit the framework, presented in Figure 1, and extend it to highlight important areas that would provide scope for further research. The key changes are in Layer I with new objectives and in Layer II with a Pre-life phase. Detailed discussions are as follows.

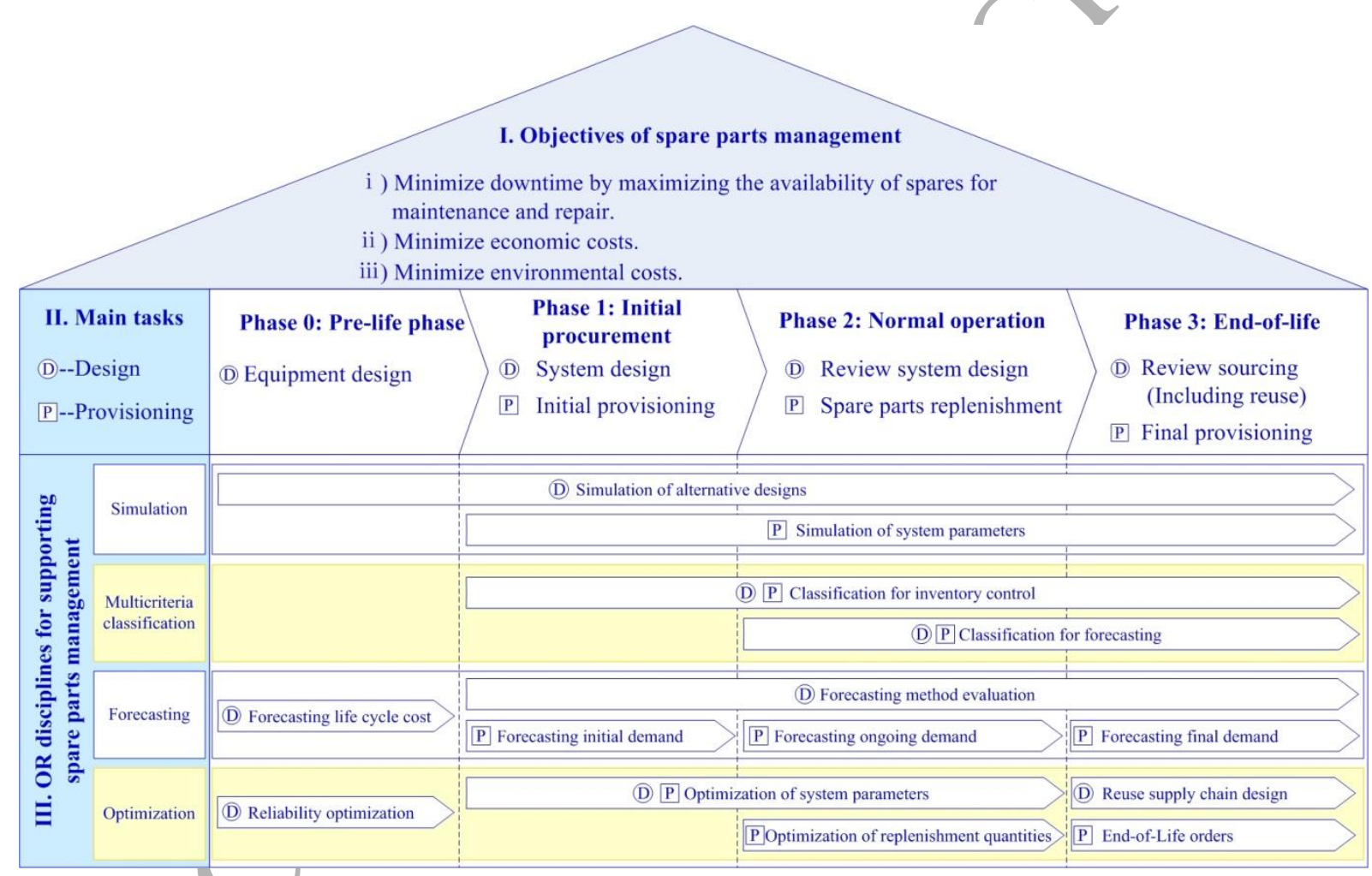

Figure.2 Extended framework for OR in spare parts management

The highest level of the framework has an altered objective i) and an additional objective iii) minimize environmental costs.

By changing objective i) we recognize that it is important to note that the availability of spares is not the ultimate aim but an intermediate objective to support the minimization of downtime. For example, the availability of spare parts may be perceived to be high ( 9 out of the 10 items available needed to repair the equipment), while in the end the service is low (the equipment cannot be repaired because of the absence of the tenth item). 
The ultimate goal of downtime minimization has been investigated in a stream of papers including Sudiarso and Labib (2002), Mirzahosseinian \& Piplani (2011), Van Jaarsveld et al. (2015), and Sun et al. (2016). Also, work by Teunter (2006) and Sun et al. (2016) investigated repair kits, finding the optimal set of parts in the kit of a repairman, where this determination is based on the trade-off between holding cost and service.

To achieve this objective may require joint optimization of maintenance and spare parts planning. The literature on this topic is limited, from our review only the following contributions investigated this: Van Horenbeek et al. (2013) (Section 5), the simulation optimization papers (Section 6.2) and software developed by the C-MORE lab (Section 7). Interested readers may also wish to refer to Alrabghi and Tiwari (2015), a recent literature review on the state of art in simulation-based optimization in maintenance, in which the authors included contributions that deal with joint optimization of maintenance and spare parts. This is an emerging area and more research is needed in order to challenge the unrealistic assumption that maintenance resources such as spare parts are always readily available.

This review has shown that the OR literature has been dominated by the first two objectives, with only a minority of papers considering environmental objectives. Yet it is not only economic considerations that are important as many people, companies and governments are concerned about environmental sustainability (Dekker et al. (2012)). In the academic literature, some studies have shown the impact of sustainability in supply chain management where the interactions between economic and environmental goals must be resolved (e.g. Digiesi et al. (2015)). Therefore, in understanding the literature on OR in spare parts management, it is important to clarify the scope of economic and environmental impacts that are modeled. The conscious decision to include environmental costs as one of the objectives is a response to practical efforts in industry as well as a call for more research. There is evidence from major research funding initiatives, such as the European Union Horizon 2020 program, of greater recognition of the need for research on environmental issues in maintenance. By considering it alongside the other two objectives, it can make a significant impact in the long run to help organizations to reduce overall costs and maintain sustainable availability of resources. However, environmental issues remain under-researched, and merit further investigation.

The next level of the framework identifies a pre-life phase (phase 0) as a precursor to the three phases in the original framework: i) initial procurement, ii) normal operation and iii) end-of-life (final phase). The OR literature has focused mainly on the normal operation phase, as it is the one which is 
most amenable to mathematical analysis. Nevertheless, some promising approaches have been identified to address the initial and final phases of the product lifecycle. In the initial phase, several inventory models have been proposed, some of which incorporate reliability-based forecasting. Judgmental forecasting methods are often used for initial procurement but there have been few research contributions in this area. In the end-of-life phase, a range of models have been developed that implicitly address the environmental risk of obsolescence but rarely do so explicitly, as part of the objective function. This relates back to the wider point of the need for more environmentally-based models.

The addition of the pre-life phase extends the product life cycle model and shows that a good spare parts strategy may already start when designing the capital equipment. This emerging research idea has been investigated by Öner et al. (2010) and Smets (2012), reviewed in Section 5.1. Also, the incorporation of design costs of a component can be derived by analysing data of previous versions of the component or data of a similar component. In general, design costs can be assumed to be an increasing convex function of the reliability level (Mettas and Kallenberg (2000)). Smets et al. (2012) also performed a life cycle cost (LCC) analysis, which included four main categories: design and development costs, production and assembly costs, operation, service and maintenance costs, and removal and disposal costs. The authors commented that the relationship between LCC and system availability is rather complex as changes in system availability can increase certain LCC components whilst lowering others. LCC analysis is inherently a forecasting exercise. To date, little attention has been paid to this issue from a forecasting perspective but there is certainly scope to do so.

The third level of the framework relates to the four OR disciplines discussed in this paper. Detailed conclusions have been giyen in previous remarks. A commonly occurring theme has been the lack of empirical testing of OR models for spare parts management. Exceptions have been noted, but many papers have relied on illustrative examples or simulation studies. Whilst such studies are valuable, it is also necessary to test new models on real data to examine how the models behave when some of their underlying assumptions may be violated.

Finally, software applications were not included in the framework, as they relate to all phases and disciplines. However, a review of software reveals a significant lag behind developments in theory. This is particularly troubling when significant empirical evidence has been found to support a new approach. It is to be hoped that this lag will diminish over time. To do so, closer partnerships are needed between researchers, software developers and users. In this way, research may become more 
relevant to practice, and practical software developments may not only reflect users' stated needs, but also the best practice identified by high quality research.

\section{References}

Alrabghi, A. and Tiwari, A. (2015) State of the art in simulation-based optimization for maintenance systems, Computers and Industrial Engineering, 82, 167-182.

Amoako-Gyampah, K., \& Meredith, J. R. (1989). The operations management research agenda: an update. Journal of Operations Management, 8(3), 250-262.

Aydin Keskin, G., \& Ozkan, C. (2013). Multiple criteria ABC analysis with FCM clustering. Journal of Industrial Engineering, Article ID 827274 (7 pages).

Ayiomamitou, N. (2016) Improving forecasting capabilities in the 3PL industry. Cardiff University, MPhil Thesis.

Bacchetti, A., Plebani, F., Saccani, N., \& Syntetos, A. (2013). Empirically-driven hierarchical classification of stock keeping units. International Journal of Production Economics, 143(2), 263-274.

Bacchetti, A., \& Saccani, N. (2012). Spare parts classification and demand forecasting for stock control: Investigating the gap between research and practice. Omega, 40(6): 722-737.

Bakker, M., Riezebos, J., \& Teunter, R.H. (2012). Review of inventory systems with deterioration since 2001. European Journal of Operational Research, 221(2): 275-284.

Barabadi, A. (2012). Reliability and spare part provision considering operational environment. A case study. International Journal of Performability Engineering, 8(5): 497-506.

Barabadi, A., Barabady, J., \& Markeset, T. (2014). Application of reliability models with covariates in spare part prediction and optimisation - A case study. Reliability Engineering and System Safety, $123,1-7$

Basten, R. J. I., \& Van Houtum, G. J. (2014). System-oriented inventory models for spare parts. Surveys in Operations Research and Management Science, 19(1), 34-55.

Bazovsky, I., \& Benz, G. (1988). Interval reliability of spare part stocks. Quality and Reliability Engineering International, 4(3): 235-246.

Behfard, S., Van der Heijden, M., Al Hanbali, A., \& Zijm, W. (2015). Last time buy and repair decisions for spare parts. European Journal of Operational Research, 244(2), 498-510.

Bhattacharya, A., Sarkar, B., \& Mukherjee, S. K. (2007). Distance-based consensus method for ABC analysis. International Journal of Production Research, 45(15), 3405-3420. 
Bijvank, M., Koole, G., \& Vis, I.F.A. (2010). Optimising a general repair kit problem with a service constraint. European Journal of Operational Research, 204(1), 76-85.

Boone, C.A., Craighead, C.W., \& Hanna, J.B. (2008). Critical challenges of inventory management in service parts supply: a Delphi Study. Operations Management Research, 1(1), 31-9.

Botter, R., \& Fortuin, L. (2000). Stocking strategy for service parts-a case study. International Journal of Operations \& Production Management, 20(6), 656-674.

Bouchery, Y., Ghaffari, A., Jemai, Z., \& Dallery, Y. (2012). Including sustainability criteria into inventory models. European Journal of Operational Research, 222(2), 229-240.

Boylan, J.E., Syntetos, A. A., \& Karakostas, G. (2008). Classification for forecasting and stock control: a case study. Journal of the Operational Research Society, 59(4), 473-481.

Boylan, J.E., \& Syntetos, A.A. (2010). Spare parts management: a review of forecasting research and extensions. IMA Journal of Management Mathematics, 21(3), 227-237.

Boylan, J.E., Goodwin, P., Mohammadipour, M., \& Syntetos, A. (2015) Reproducibility in Forecasting Research, International Journal of Forecasting, 31 (1), 79-90.

Boylan, J.E., \& Syntetos, A.A. (2016) Forecasting: academia versus business. Commentary: It takes two to tango. Foresight: The International Journal of Applied Forecasting, 42, $26-29$.

Braglia, M., Grassi, A., \& Montanari, R. (2004). Multi-attribute classification method for spare parts inventory management. Journal of Quality in Maintenance Engineering, 10(1), 55-65.

Burton, R. W., \& Jaquette, S. C. (1973). The initial provisioning decision for insurance type items. Naval Research Logistics Quarterly, 20(1), 123-146.

Buyukkaramikli, N. C., Van Ooijen, H. P., \& Bertrand, J. W. M. (2015). Integrating inventory control and capacity management at a maintenance service provider. Annals of Operations Research, 231(1), 185-206.

Cakir, O., \& Canbolat, M. S. (2008). A web-based decision support system for multi-criteria inventory classification using fuzzy AHP methodology. Expert Systems with Applications, 35(3), $1367-1378$.

Cavalieri, S., Garetti, M., Macchi, M., \& Pinto, R. (2008). A decision-making framework for managing maintenance spare parts. Production Planning \& Control, 19(4), 379-396.

Çebi, F., Kahraman, C., \& Bolat, B. (2010). A multiattribute ABC classification model using fuzzy AHP. Paper presented at the 40th International Conference on Computers and Industrial Engineering (CIE), doi: 10.1109/ICCIE.2010.5668233 
Chakravarty, A. K. (1981). Multi-Item Inventory Aggregation into Groups. Journal of the Operational Research Society, 32(1), 19-26.

Chen, F.-L., Chen, Y.-C., \& Kuo, J.-Y. (2010). Applying moving back-propagation neural network and moving fuzzy neuron network to predict the requirement of critical spare parts. Expert Systems with Applications, 37(6), 4358-4367.

Chen, J.-X. (2011). Peer-estimation for multiple criteria ABC inventory classification. Computers \& Operations Research, 38(12), 1784-1791.

Chen, J.-X. (2012). Multiple criteria ABC inventory classification using two virtual items. International Journal of Production Research, 50(6), 1702-1713.

Chen, Y., Li, K. W., Kilgour, D. M., \& Hipel, K. W. (2008). A case-based distance model for multiple criteria ABC analysis. Computers \& Operations Research, 35(3), 776-796.

Chen, Y., Li, K. W., Levy, J., Hipel, K. W., \& Kilgour, D. M. (2008). A rough set approach to multiple criteria ABC analysis, Transactions on Rough Sets VIII (pp. 35-52), Springer.

Cheng, Y. H., \& Tsao, H. L. (2010). Rolling stock maintenance strategy selection, spares parts estimation, and replacements' interval calculation. International Journal of Production Economics, 128(1), 404-412.

Chu, C.-W., Liang, G.-S., \& Liao, C.-T. (2008). Controlling inventory by combining ABC analysis and fuzzy classification. Computers \& Industrial Engineering, 55(4), 841-851.

C-MORE, Spares Management Software (SMS), CMORE University of Toronto, Ver 2.00.0, 2013.

Costantino, F., Di Gravio, G., \& Tronci, M. (2013). Multi-echelon, multi-indenture spare parts inventory control subject to system availability and budget constraints. Reliability Engineering \& System Safety, 119, 95-101.

de Smidt-Destombes, K. S., Van der Heijden, M. C., \& Van Harten, A. (2004). On the availability of a k-out-of-N/system given limited spares and repair capacity under a condition based maintenance strategy. Reliability Engineering \& System Safety, 83(3), 287-300.

de Smidt-Destombes, K. S., Van der Heijden, M. C., \& Van Harten, A. (2006). On the interaction between maintenance, spare part inventories and repair capacity for a k-out-of-N system with wear-out. European Journal of Operational Research, 174(1), 182-200.

de Smidt-Destombes, K. S., Van der Heijden, M. C., \& Van Harten, A. (2007). Availability of k-out-of-N systems under block replacement sharing limited spares and repair capacity. International Journal of Production Economics, 107(2), 404-421. 
de Smidt-Destombes, K. S., Van der Heijden, M. C., \& Van Harten, A. (2009). Joint optimisation of spare part inventory, maintenance frequency and repair capacity for k-out-of-N systems. International Journal of Production Economics, 118(1), 260-268.

Dekker, R., Bloemhof, J., \& Mallidis, I. (2012). Operations Research for green logistics-An overview of aspects, issues, contributions and challenges. European Journal of Operational Research, 219(3), 671-679.

Diaz, A., \& Fu, M. C. (1997). Models for multi-echelon repairable item inventory systems with limited repair capacity. European Journal of Operational Research, 97(3), 480-492.

Digiesi, S., Mossa, G., \& Rubino, S. (2015). A sustainable EOQ model for repairable spare parts under uncertain demand. IMA Journal of Management Mathematics, 26(2), 185-203.

Driessen, M., Arts, J., Van Houtum, G.J., Rustenburg J.W., \& Huisman, B. (2015). Maintenance spare parts planning and control: A framework for control and agenda for future research. Production Planning \& Control: the Management of Operations, 26(5), 407-426.

Dubi, A. (2006). The Monte Carlo method and optimisation of spare parts in complex realistic scenarios. Paper presented at the RAMS'06 Annual Reliability and Maintainability Symposium.

Duffuaa, S., Ben-Daya, M., Al-Sultan, K., \& Andijani, A. (2001). A generic conceptual simulation model for maintenance systems. Journal of Quality in Maintenance Engineering, 7(3), 207-219.

Eaves, A. H. C. (2002). Forecasting for the ordering and stock-holding of consumable spare parts. Unpublished PhD thesis, Lancaster University.

Eaves, A., \& Kingsman, B. (2004). Forecasting for the ordering and stock-holding of spare parts. Journal of the Operational Research Society, 55(4), 431-437.

Eren, B., \& Erol, S. (2015). The Proposal of Demand Estimation of Repairable Items for the Weapon Systems During the Initial Provisioning Period: F-16 Case Study. In Military Logistics (pp. 43-71). Springer International Publishing.

Exton, T., \& Labib, A. (2002). Spare parts decision analysis-The missing link in CMMSs (Part II). Journal of Maintenance \& Asset Management, 17(1), 14-21.

Fildes, R. (1992). The evaluation of extrapolative forecasting methods. International Journal of Forecasting, 8(1), 81-98.

Fildes, R., Goodwin, P., Lawrence, M., \& Nikolopoulos, K. (2009). Effective forecasting and judgmental adjustments: an empirical evaluation and strategies for improvement in supply-chain planning. International Journal of Forecasting, 25(1), 3-23. 
Fleischmann, M., Van Nunen, J. A., \& Gräve, B. (2003). Integrating closed-loop supply chains and spare-parts management at IBM. Interfaces, 33(6), 44-56.

Flores, B. E., \& Clay Whybark, D. C. (1986). Multiple criteria ABC analysis. International Journal of Operations \& Production Management, 6(3), 38-46.

Flores, B. E., \& Clay Whybark, D. C. (1987). Implementing multiple criteria ABC analysis. Journal of Operations Management, 7(1), 79-85.

Flores, B. E., Olson, D. L., \& Dorai, V. (1992). Management of multicriteria inventory classification. Mathematical and Computer Modelling, 16(12), 71-82.

Foote, B. L. (1995). On the implementation of a control-based forecasting system for aircraft spare parts procurement. IIE transactions, 27(2), 210-216.

Fortuin, L. (1980). The all-time requirement of spare parts for service after sales-theoretical analysis and practical results. International Journal of Operations \& Production Management, 1(1), 59-70.

Fortuin, L. (1981). Reduction of the all-time requirement for spare parts. International Journal of Operations \& Production Management, 2(1), 29-37.

Fortuin, L. (1984). Initial supply and re-order level/of new service parts. European Journal of Operational Research, 15(3), 310-319.

Fortuin, L., \& Martin, H. (1999). Control of service parts. International Journal of Operations \& Production Management, 19(9), 950-971.

Frazzon, E. M., Israel, E., Albrecht, A., Pereira, C. E., \& Hellingrath, B. (2014). Spare parts supply chains' operational planning using technical condition information from intelligent maintenance systems. Annual Reviews in Control, 38(1), 147-154.

Gallagher, T., Mitchke, M. D., \& Rogers, M. C. (2005). Profiting from spare parts. The McKinsey Quarterly, February 2005, http://www.werc.org/assets/1/workflow staging/Publications/666.pdf

Ghobbar A.A., \& Friend, C.H. (2002) Sources of intermittent demand for aircraft spare parts within airline operations. Journal of Air Transport Management, 8(4), 221-231.

Ghobbar, A. A., \& Friend, C. H. (2003). Evaluation of forecasting methods for intermittent parts demand in the field of aviation: a predictive model. Computers \& Operations Research, 30(14), 2097-2114.

Ghodrati, B. (2005). Reliability and Operational Environment Based Spare Parts Planning. Lulea University of Technology, Unpublished PhD Thesis. 
Ghodrati, B., Benjevic, D., \& Jardine, A. (2012),"Product support improvement by considering system operating environment", International Journal of Quality \& Reliability Management, 29(4), 436 $-450$.

Ghodrati, B., \& Kumar, U. (2005) Reliability and operating environment-based spare parts estimation: a case study from Kiruna Mine, Sweden. Journal of Quality in Maintenance Engineering, 11(2), 169-84.

Ghodrati, B. (2006). Weibull and exponential renewal models in spare parts estimation: a comparison. International Journal of Performability Engineering, 2(2), 135-47.

Ghodrati, B., Ahmadi, A., \& Galar, D. (2013). Spare parts estimation for machine availability improvement addressing its reliability and operating environment- case study. International Journal of Reliability, Quality and Safety Engineering, 20(3), 134005 (15 pages).

Gilliland M. (2002). Is forecasting a waste of time? Supply Chain Management Review, 6(4), 16-23.

Gross, D., Miller, D., \& Soland, R. (1985). On some common interests among reliability, inventory and queuing. IEEE Transactions on Reliability, 34 (3), 204-208.

Guide, V. D. R., \& Srivastava, R. (1997). Repairable inventory theory: Models and applications. European Journal of Operational Research, 102(1), 1-20.

Gutierrez, R. S., Solis, A. O., \& Mukhopadhyay, S. (2008). Lumpy demand forecasting using neural networks. International Journal of Production Economics, 111(2), 409-420.

Guvenir, H. A., \& Erel, E. (1998). Multicriteria inventory classification using a genetic algorithm. European journal of Operational Research, 105(1), 29-37.

Hadi-Vencheh, A. (2010). An improvement to multiple criteria ABC inventory classification. European Journal of Operational Research, 201(3), 962-965.

Hadi-Vencheh, A., \& Mohamadghasemi, A. (2011). A fuzzy AHP-DEA approach for multiple criteria ABC inventory classification. Expert Systems with Applications, 38(4), 3346-3352.

Haneveld, W. K., \& Teunter, R. (1997). Optimal provisioning strategies for slow moving spare parts with small lead times. Journal of the Operational Research Society, 48(2), 184-194.

Hariga, M. (1996). Optimal EOQ models for deteriorating items with time-varying demand. Journal of the Operational Research Society, 47(10), 1228-1246.

Hatefi, S., Torabi, S., \& Bagheri, P. (2014). Multi-criteria ABC inventory classification with mixed quantitative and qualitative criteria. International Journal of Production Research, 52(3), 776-786. 
Heinecke, G., Syntetos, A., \& Wang, W. (2013). Forecasting-based SKU classification. International Journal of Production Economics, 143(2), 455-462.

Helmrich, M. J. R., Jans, R., Van den Heuvel, W., \& Wagelmans, A. P. (2015). The economic lot-sizing problem with an emission capacity constraint. European Journal of Operational Research, 241(1), $50-62$.

Hu, Q., Chakhar, S., Siraj, S., \& Labib, A. (2017) Spare parts classification in industrial manufacturing using the dominance-based rough set approach, European Journal of Operational Research, http://dx.doi.org/10.1016/i.ejor.2017.04.040.

Hua, Z., \& Zhang, B. (2006). A hybrid support vector machines and logistic regression approach for forecasting intermittent demand of spare parts. Applied Mathematics and Computation, 181(2), 1035-1048.

Hua, Z.S., Zhang, B., Yang, J., \& Tan, D.S. (2007) A new approach of forecasting intermittent demand for spare parts inventories in the process industries. Journal of the Operational Research Society, $58(1), 52-61$.

Huiskonen, J. (2001). Maintenance spare parts logistics: Special characteristics and strategic choices. International Journal of Production Economics, 71(1), 125-133.

Hyndman RJ. (2006). Another look at forecast-accuracy metrics for intermittent demand. Foresight: the International Journal of Applied Forecasting, 4, 43-46.

Inderfurth, K., \& Kleber, R. (2013). An advanced heuristic for multiple-option spare parts procurement after end-of-production. Production and Operations Management, 22(1), 54-70.

Inderfurth, K., \& Mukherjee, K. (2008). Decision support for spare parts acquisition in post product life cycle. Central European Journal of Operations Research, 16(1), 17-42.

Jahangirian, M., Eldabi, T., Naseer, A., Stergioulas, L. K., \& Young, T. (2010). Simulation in manufacturing and business: A review. European Journal of Operational Research, 203(1), 1-13.

Jamshidi, H., \& Jain, A. (2008). Multi-criteria ABC inventory classification: With exponential smoothing weights. Journal of Global Business Issues, 2(1), 61-67.

Jaquette, D. L., \& Osaki, S. (1972). Initial Provisioning of a Standby System with Deteriorating and Repairable Spares. IEEE Transactions on Reliability, 21(4), 245-247.

Jardine, A. K., Lin, D., \& Banjevic, D. (2006). A review on machinery diagnostics and prognostics implementing condition-based maintenance. Mechanical Systems and Signal Processing, 20(7), 1483-1510. 
Jardine, AKS. \& Tsang, A.H.C. (2013) Maintenance replacement, and reliability: Theory and Appications, CRC Press.

Jin, T., \& Liao, H. (2009). Spare parts inventory control considering stochastic growth of an installed base. Computers \& Industrial Engineering, 56(1), 452-460.

Jin, T., \& Tian, Y. (2012). Optimising reliability and service parts logistics for a time-varying installed base. European Journal of Operational Research, 218(1), 152-162.

Jin, T., Tian, Z., \& Xie, M. (2015). A game-theoretical approach for optimising maintenance, spares and service capacity in performance contracting. International Journal of Production Economics, 161 (March 2015), 31-43.

Johnston, F. R., \& Boylan, J. E. (1996). Forecasting for items with intermittent demand. Journal of the Operational Research Society, 47(1), 113-121.

Jung, W. (1993). Recoverable inventory systems with time-varying demand. Production and Inventory Management Journal, 34(1), 77-81.

Kabir, A. Z., \& Farrash, S. (1996). Simulation of an integrated age replacement and spare provisioning policy using SLAM. Reliability Engineering \& System Safety, 52(2), 129-138.

Kabir, G., \& Hasin, M. A. (2012). Multiple criteria inventory classification using fuzzy analytic hierarchy process. International Journal of Industrial Engineering Computations, 3(2), 123-132.

Kabir, G., \& Hasin, M. A. (2013). Multi-criteria inventory classification through integration of fuzzy analytic hierarchy process and artificial neural network. International Journal of Industrial and Systems Engineering, 14(1), 74-103.

Kader, B., Sofiene, D., Nidhal, R., \& Walid, E. (2015). Ecological and joint optimisation of preventive maintenance and spare parts inventories for an optimal production plan. IFAC-PapersOnLine, $48(3), 2139-2144$

Kennedy, W.J., Patterson, J. W, \& Fredendall, L.D. (2002). An overview of recent literature on spare parts inventories. International Journal of Production Economics, 76(2), 201-215.

Khanra, S., Ghosh, S., \& Chaudhuri, K. (2011). An EOQ model for a deteriorating item with time dependent quadratic demand under permissible delay in payment. Applied Mathematics and Computation, 218(1), 1-9.

Khanra, S., Mandal, B., \& Sarkar, B. (2013). An inventory model with time dependent demand and shortages under trade credit policy. Economic Modelling, 35, 349-355.

Kleber, R., Schulz, T., \& Voigt, G. (2012). Dynamic buy-back for product recovery in end-of-life spare 
parts procurement. International Journal of Production Research, 50(6), 1476-1488.

Klepper, S. (1996) Entry, Exit, Growth, and Innovation Over the Product Life Cycle, The American Economic Review, 86(3), 562-583.

Kostenko, A., \& Hyndman, R. (2006). A note on the categorisation of demand patterns. Journal of the Operations Research Society, 57(10), 1256-1257.

Kourentzes, N. (2013). Intermittent demand forecasts with neural networks. International Journal of Production Economics, 143(1), 198-206.

Krikke, H., \& Van der Laan, E. (2011). Last Time Buy and control policies with phase-out returns: a case study in plant control systems. International Journal of Production Research, 49(17), 5183-5206.

Kumar, N., \& Vrat, P. (1994). A simulation study of unit exchange spares management of diesel locomotives in the Indian Railways. International Journal of Production Economics, 33(1), 225-236.

Kumar, U.D., \& Knezevic, J. (1998). Availability based spare optimisation using renewal process. Reliability Engineering and System Safety, 59(2), 217-23.

Labib, A., \& Exton, T. (2001). Spare parts decision analysis-the missing link in CMMS's (Part 1). Journal of Maintenance \& Asset Management, 16(3), 10-17.

Labib, A.W. (1998). World Class Maintenance Using a Computerised Maintenance Management System. Journal of Quality in Maintenance Engineering, 4(1), 66-75.

Labib, A.W. (2003). Computerised Maintenance Management Systems (CMMSs): A black hole or a black box?. Journal of Maintenance \& Asset Management, 18(3), 16-21.

Ladhari, T., Babai, M. Z., \& Lajili, I. (2016). Multi-criteria inventory classification: new consensual procedures. IMA Journal of Management Mathematics, 27(2), 335-351.

Lau, H. C., \& Song, H. (2004). Two-echelon repairable item inventory system with limited repair capacity under nonstationary demands. 35th Meeting of the Decision Sciences Institute (DSI).

Lau, H. C., \& Song, H. (2008). Multi-echelon repairable item inventory system with limited repair capacity under nonstationary demands. International Journal of Inventory Research, 1(1), 67-92.

Lau, H. C., Song, H., See, C. T., \& Cheng, S. Y. (2006). Evaluation of time-varying availability in multi-echelon spare parts systems with passivation. European Journal of Operational Research, 170(1), 91-105.

Lee, L. H., Chew, E. P., Teng, S., \& Chen, Y. (2008). Multi-objective simulation-based evolutionary 
algorithm for an aircraft spare parts allocation problem. European Journal of Operational Research, 189(2), 476-491.

Li, S., \& Kuo, X. (2008). The inventory management system for automobile spare parts in a central warehouse. Expert Systems with Applications, 34(2), 1144-1153.

Liu, J., Liao, X., Zhao, W., \& Yang, N. (2016). A classification approach based on the outranking model for multiple criteria ABC analysis. Omega, 61(June 2016), 19-34.

Lolli, F., Ishizaka, A., \& Gamberini, R. (2014). New AHP-based approaches for multi-criteria inventory classification. International Journal of Production Economics, 156 (October 2014), $62-74$.

Louit, D., Pascual, R., Banjevic, D., \& Jardine, A. K. (2011). Condition-based spares ordering for critical components. Mechanical Systems and Signal Processing, 25(5), 1837-1848.

Makridakis, S., \& Hibon, M. (2000) The M3-Competition: results, conclusions and implications. International Journal of Forecasting, 16(4), 451-476.

Makridakis, S., Andersen, A., Carbone, R., Fildes, R., Hibon, M., Lewandowski, R., Newton, J., Parzen, E., \& Winkler, R. (1982). The accuracy of extrapolation (time series) methods: results of a forecasting competition. Journal of Forecasting, 1(2), 111-153.

Mani, V., \& Sarma, VVS. (1984). Queuing network models for aircraft availability and spares management. IEEE Transactions on Reliability, 33(3): 257-62.

Marseguerra, M., Zio, E., \& Podofillini,L. (2005). Multiobjective spare part allocation by means of genetic algorithms and Monte Carlo simulation. Reliability Engineering \& System Safety, 87(3), $325-335$.

Mettas, A., \& Kallenberg, R. (2000). Reliability allocation and optimization for complex systems, in: Proceedings of the Annual Reliability and Maintainability Symposium, 216-221.

Millstein, M. A., Yang, L., \& Li, H. (2014). Optimising ABC inventory grouping decisions. International Journal of Production Economics, 148 (February 2014), 71-80.

Mirzahosseinian, H., \& Piplani, R. (2011). A study of repairable parts inventory system operating under performance-based contract, European Journal of Operational Research 214(2), 256-261.

Mohammaditabar, D., Ghodsypour, S. H., \& O'Brien, C. (2012). Inventory control system design by integrating inventory classification and policy selection. International Journal of Production Economics, 140(2), 655-659.

Molenaers, A., Baets, H., Pintelon, L., \& Waeyenbergh, G. (2012). Criticality classification of spare 
parts: A case study. International Journal of Production Economics, 140(2), 570-578.

Montgomery N., Banjevic, D., \& Jardine, AKS. (2014). The effect of deterioration on spare parts holding. Reliability and Maintainability Simposium (RAMS) 2014, IEEE Explore, pp 1-6.

Ng, W. L. (2007). A simple classifier for multiple criteria ABC analysis. European Journal of Operational Research, 177(1), 344-353.

Öner, K.B., Kiesmüller, G.P. , \& Van Houtum , G.J. (2010). Optimization of component reliability in the design phase of capital goods. European Journal of Operational Research, 205, 615-624.

Pall, R. (2008). On the availability of the CH149 Cormorant fleet. Paper presented at the WSC Winter Simulation Conference.

Pannirselvam, G. P., Ferguson, L. A., Ash, R. C., \& Siferd, S. P. (1999). Operations management research: an update for the 1990s. Journal of Operations Management, 18(1), 95-112.

Park, J., Bae, H., \& Bae, J. (2014). Cross-evaluation-based weighted linear optimisation for multi-criteria ABC inventory classification. Computers \& Industrial Engineering, 76, 40-48.

Partovi, F. Y., \& Anandarajan, M. (2002). Classifying inventory using an artificial neural network approach. Computers \& Industrial Engineering, 41(4), 389-404.

Partovi, F. Y., \& Burton, J. (1993). Using the analytic hierarchy process for ABC analysis. International Journal of Operations \& Production Management, 13(9), 29-44.

Paterson, C., Kiesmüller, G., Teunter, R., \& Glazebrook, K. (2011). Inventory models with lateral transshipments: A review. European Journal of Operational Research, 210(2): 125-136.

Pérès, F., \& Grenouilleau, J.-C. (2002). Initial spare parts supply of an orbital system. Aircraft Engineering and Aerospace Technology, 74(3), 252-262.

Persson, F., \& Saccani, N. (2007). Managing the After Sales Logistic Network-A Simulation Study of a Spare Parts Supply Chain. Advances in Production Management Systems, Springer.

Persson, F., \&/Saccani, N. (2009). Managing the after-sales logistic network-a simulation study. Production Planning and Control, 20(2), 125-134.

Pourakbar, M., \& Dekker, R. (2012). Customer differentiated end-of-life inventory problem. European Journal of Operational Research, 222(1), 44-53.

Pourakbar, M., Frenk, J. B. G., \& Dekker, R. (2012). End-of-Life Inventory Decisions for Consumer Electronics Service Parts. Production and Operations Management, 21(5), 889-906.

Pourakbar, M., Laan, E., \& Dekker, R. (2014). End-of-Life Inventory Problem with Phaseout Returns. Production and Operations Management, 23(9), 1561-1576. 
Ramanathan, R. (2006). ABC inventory classification with multiple-criteria using weighted linear optimisation. Computers \& Operations Research, 33(3), 695-700.

Rappold, J. A., \& Van Roo, B. D. (2009). Designing multi-echelon service parts networks with finite repair capacity. European Journal of Operational Research, 199(3), 781-792.

Regattieri, A., Gamberi, M., Gamberini, R., \& Manzini, R. (2005). Managing lumpy demand for aircraft spare parts. Journal of Air Transport Management, 11(6), 426-431.

Rezaei, J., \& Dowlatshahi, S. (2010). A rule-based multi-criteria approach to inventory classification. International Journal of Production Research, 48(23), 7107-7126.

Rink, D.R., \& Swan, J.E. (1979) Product Life Cycle Research: A Literature Review, Journal of Business Research, 7(3), 219-242.

Robinson, S. (2004). Simulation: the practice of model development and use. Palgrave Macmillan.

Romeijnders, W., Teunter, R., \& Van Jaarsveld, W. (2012). A two-step method for forecasting spare parts demand using information on component repairs. European Journal of Operational Research, 220(2), 386-393.

Rossetti, M. D., \& Thomas, S. (2006). Object-oriented multi-indenture multi-echelon spare parts supply chain simulation model. International Jourmal of Modelling \& Simulation, 26(4), 359-369.

Rustenburg, W. D., Van Houtum, G. J., \& Zijm, W. H. M. (2001). Spare parts management at complex technology-based organisations: An agenda for research. International Journal of Production Economics, 71(1), 177-193.

Saaty, T. L. (1980). The Analytic Hierarchy Process. New York: McGraw-Hill.

Sarker, R., \& Haque, A. (2000). Optimisation of maintenance and spare provisioning policy using simulation. Applied Mathematical Modelling, 24(10), 751-760.

Schröter, M., \& Spengler, T. (2005). A system dynamics model for strategic management of spare parts in closed-loop supply chains. Paper in the Proceedings of the 23rd International Conference of the System Dynamics Society.

Schweitzer, P. J. (1967). Initial provisioning with spare deterioration. Operations Research, 15(3), 513-529.

Silver, E A. (1981). Operations research in inventory management: A review and critique. Operations Research, 29(4), 628-645.

Sleptchenko, A., Van der Heijden, M., \& Van Harten, A. (2002). Effects of finite repair capacity in 
multi-echelon, multi-indenture service part supply systems. International Journal of Production Economics, 79(3), 209-230.

Sleptchenko, A., Van der Heijden, M., \& Van Harten, A. (2003). Trade-off between inventory and repair capacity in spare part networks. Journal of the Operational Research Society, 54(3), 263-272.

Sleptchenko, A., Van der Heijden, M., \& Van Harten, A. (2005). Using repair priorities to reduce stock investment in spare part networks. European Journal of Operational Research, 163(3), 733-750.

Smets, L, Van Houtum, G.J., \& Langerak, F. (2012). Deign for availability: A holistic approach to create value for manufacturers and customers of capital goods. Journal of Systems Science and Systems Engineering, 21(4), 403-421.

Song, Y., \& Yang, J.-H. (2015). Simulation of dynamics behaviors for shipping equipment support with system dynamics analysis approach. Journal of Industrial Engineering and Management, 8(3), 636-657.

Soylu, B., \& Akyol, B. (2014). Multi-criteria inventory classification with reference items. Computers \& Industrial Engineering, 69(March 2014), 12-20.

Spengler, T., \& Schröter, M. (2003). Strategic management of spare parts in closed-loop supply chains - a system dynamics approach. Interfaces, 33(6), 7-17.

Sterman, J. D. (2000). Business Dynamics. Systems Thinking and Modelling for a Complex World. McGraw-Hill, Boston, MA.

Stevenson, W. J. (2012). Operations Management. New York: McGraw-Hill/Irwin.

Sudiarso A., \& Labib AW. (2002). A fuzzy logic approach to the maintenance/production scheduling algorithm. International Journal of Production Research, 40(13), 3121-3138.

Sun, Y., Chen, X., Ren, H., Jin, Y., \& Liu, Q. (2016). Ordering decision-making methods on spare parts for a new aircraft fleet based on a two-sample prediction, Reliability Engineering and System Safety, 156, 40-50.

Syntetos, A.A. (2001). Forecasting of intermittent demand. Unpublished Ph.D. thesis, Buckinghamshire Chilterns University College, Brunel University, UK.

Syntetos, A. A., \& Boylan, J. E. (2001). On the bias of intermittent demand estimates. International Journal of Production Economics, 71(1), 457-466.

Syntetos, A. A., \& Boylan, J. E. (2005). The accuracy of intermittent demand estimates. International Journal of forecasting, 21(2), 303-314. 
Syntetos, A.A., Boylan, J.E., \& Croston, J. (2005). On the categorisation of demand patterns. Journal of the Operational Research Society, 56(5), 495-503.

Syntetos, A. A., \& Boylan, J. E. (2006). On the stock control performance of intermittent demand estimators. International Journal of Production Economics, 103(1), 36-47.

Syntetos, A.A., Boylan J.E., \& Disney. S.M. (2009a). Forecasting for inventory planning: a 50-year review. Journal of the Operational Research Society, 60, Supplement 1: Milestones in OR (May 2009), 149-160.

Syntetos, A. A., Nikolopoulos, K., Boylan, J. E., Fildes, R., \& Goodwin, P. (2009b). The effécts of integrating management judgement into intermittent demand forecasts. International Journal of Production Economics, 118(1), 72-81.

Syntetos, A. A., Babai, M. Z., \& Altay, N. (2012). On the demand distributions of spare parts. International Journal of Production Research, 50(8), 2101-2117.

Syntetos, A., Lengu, D., \& Babai, M. Z. (2013). A note on the demand distributions of spare parts. International Journal of Production Research, 51(21), 6356-6358.

Syntetos, A. A., Babai, M. Z., \& Gardner, E. S. (2015). Forecasting intermittent inventory demands: simple parametric methods vs. bootstrapping. Journal of Business Research, 68(2015), $1746-1752$.

Syntetos, A., Babai, Z., Boylan, J., Kolassa, S., \& Nikolopoulos, K. (2016). Supply Chain Forecasting: Theory, Practice, their Gap and the Future. European Journal of Operational Research, 252(1), $1-26$.

Teunter, R.H. (2006). The multiple-job repair kit problem. European Journal of Operational Research, $175(2), 1103-1116$.

Teunter, R. H., \& Duhcan, L. (2009). Forecasting intermittent demand: a comparative study. Journal of the Operational Research Society, 60(3), 321-329.

Teunter, R. H., \& Fortuin, L. (1998). End-of-life service: A case study. European Journal of Operational Research, 107(1), 19-34.

Teunter, R. H., \& Fortuin, L. (1999). End-of-life service. International Journal of Production Economics, 59(1), 487-497.

Teunter, R.H., \& Haneveld, W. K. K. (1998). The 'final orders problem. European Journal of Operational Research, 107(1), 35-44.

Teunter, R.H., \& Haneveld, W. K. K. (2002a). Inventory control of service parts in the final phase. 
European Journal of Operational Research, 137(3), 497-511.

Teunter, R.H., \& Haneveld, W. K. K. (2002b). Inventory control of service parts in the final phase: A central depot and repair kits. European Journal of Operational Research, 138(1), 76-86.

Teunter, R. H., Babai, M. Z., \& Syntetos, A. A. (2010). ABC classification: service levels and inventory costs. Production and Operations Management, 19(3), 343-352.

Teunter, R. H., Syntetos, A. A., \& Babai, M. Z. (2011). Intermittent demand: Linking forecasting to inventory obsolescence. European Journal of Operational Research, 214(3), 606-615.

Teunter, R.H., \& Sani, B. (2009). On the bias of Croston's forecasting method. European Joyrnal of Operational Research, 194(1), 177-183.

Thierry, M., Salomon, M., Van Nunen, J., \& Van Wassenhove, L. (1995). Strategic issues in product recovery management. California Management Review, 37(2), 114-135.

Tiacci, L., \& Saetta, S. (2011). Reducing the mean supply delay of spare parts using lateral transshipments policies. International Journal of Production Economics, 133(1), 182-191.

Tian, J., \& Zhao, T. (2009). System dynamics in supply support of spare parts. Paper presented at the 8th International Conference on Reliability, Maintainability and Safety. ICRMS 2009.

Torabi, S., Hatefi, S., \& Pay, B. S. (2012). ABC inyentory classification in the presence of both quantitative and qualitative criteria. Computers \& Industrial Engineering, 63(2), 530-537.

Tracht, K., Goch, G., Schuh, P., Sorg, M., \& Westerkamp, J. F. (2013). Failure probability prediction based on condition monitoring data of wind energy systems for spare parts supply. CIRP Annals-Manufacturing Technology, 62(1), 127-130.

Tsai, C.-Y., \& Yeh, S.-W. (2008). A multiple objective particle swarm optimisation approach for inventory classification. International Journal of Production Economics, 114(2), 656-666.

Van Horenbeek, A., Buré, J., Cattrysse, D., Pintelon, L., \& Vansteenwegen, P. (2013). Joint maintenance and inventory optimisation systems: A review. International Journal of Production Economics, 143(2), 499-508.

Van Jaărsveld, W., \& Dekker, R. (2011). Spare parts stock control for redundant systems using reliability centred maintenance data. Reliability Engineering \& System Safety, 96(11), 1576-1586.

Van Jaarsveld, W., Dollevoet, T., \& Dekker, R. (2015). Improving spare parts inventory control at a repair shop. Omega, 57, Part B (December 2015), 217-229.

Van Jaarsveld, W., \& Scheller-Wolf, A. (2015). Optimization of industrial-scale assemble-to-order systems, INFORMS Journal on Computing, 27(3), 544-560. 
Van Kooten, J. P., \& Tan, T. (2009). The final order problem for repairable spare parts under condemnation. Journal of the Operational Research Society, 60(10), 1449-1461.

Van Wingerden, E., Basten, R.J.I., Dekker, R., \& Rustenburg, W.D. (2014). More grip on inventory control through improved forecasting: A comparative study at three companies, International Journal of Production Economics, 157(November 2014), 220-237.

Viswanathan, S., \& Zhou, C. (2008). A new bootstrapping based method for forecasting and safety stock determination for intermittent demand items. Working paper, Nanyang Business School, Nanyang Technological University, Singapore.

Walker, J. (1996). A graphical aid for the initial purchase of 'insurance type' spares. Journal of the Operational Research Society, 47(10), 1296-1300.

Wang, L., Chu, J., \& Mao, W. (2009). A condition-based replacement and spare provisioning policy for deteriorating systems with uncertain deterioration to failure. European Journal of Operational Research, 194(1), 184-205.

Wang, W. (2011). A joint spare part and maintenance inspection optimisation model using the delay-time concept. Reliability Engineering \& System Safety, 96(11), 1535-1541.

Wang, W., \& Syntetos, A. A. (2011). Spare parts demand: Linking forecasting to equipment maintenance. Transportation Research Part E: Logistics and Transportation Review, 47(6), 1194-1209.

Willemain, T. R., Smart, C. N., \& Schwarz, H. F. (2004). A new approach to forecasting intermittent demand for service parts inventories. International Journal of Forecasting, 20(3), 375-387.

Williams, T. (1984). Stock control with sporadic and slow-moving demand. Journal of the Operational Research Society, 35(10), 939-948.

Wu, P., Hung, Y.-Y,, \& Lin, Z.-p. (2014). Intelligent forecasting system based on integration of electromagnetism-like mechanism and fuzzy neural network. Expert Systems with Applications, $41(6), 2660-2677$.

Yelland, P. M. (2010). Bayesian forecasting of parts demand. International Journal of Forecasting, 26(2), 374-396.

Yu, M.-C. (2011). Multi-criteria ABC analysis using artificial-intelligence-based classification techniques. Expert Systems with Applications, 38(4), 3416-3421.

Zhang, R. Q., Hopp, W. J., \& Supatgiat, C. (2001). Spreadsheet implementable inventory control for a distribution center. Journal of Heuristics, 7(2), 185-203. 
Zhao, J.M., Hu, Q.W., \& Tian, Y. (2015). A simulation model of spare inventory with complex conditions.In: Sheng, A., \& Wang, Y. (2015) Manufacuring and Engineering Technology, Proceedings of the 2014 International Conference Manufacturing and Engineering Technology, CRC Press (pp. 573-576).

Zhou, C., \& Viswanathan, S. (2011). Comparison of a new bootstrapping method with parametric approaches for safety stock determination in service parts inventory systems. International Journal of Production Economics, 133(1), 481-485.

Zhou, P., \& Fan, L. (2007). A note on multi-criteria ABC inventory classification using weighted linear optimisation. European Journal of Operational Research, 182(3), 1488-1491. 
Appendix A: Classification approaches applied to MCIC

\begin{tabular}{|l|l|}
\hline \multicolumn{1}{|c|}{ Reference } & \multicolumn{1}{|c|}{ The proposed approach } \\
\hline Guvenir\& Erel (1998) & Genetic algorithm \\
\hline Flores\& Whybark (1986, 1987) & Bi-criteria matrix \\
\hline Flores et al. (1992), Partovi \& Burton (1993) & AHP proposed by Saaty (1980) \\
\hline Partovi \& Anandarajan (2002) & Multilayer perceptions \\
\hline Ramanathan (2006) & Weighted linear optimization \\
\hline Bhattacharya et al. (2007) & TOPSIS \\
\hline Zhou\& Fan (2007) & Extended version of Ramanathan (2006) \\
\hline Ng (2007) & Modified weight linear optimization \\
\hline $\begin{array}{l}\text { Cakir\& Canbolat (2008), ÇEbi et al. (2010), Kabir } \\
\text { \& Hasin (2012) }\end{array}$ & Fuzzy AHP \\
\hline Chen et al. (2008a) & Extended version of Ng (2007) \\
\hline Chen et al. (2008b), Hu et al. (2017) & Fuzzy Logic \\
\hline Chu et al. (2008) & Fuzzinance-based rough set approach \\
\hline Jamshidi \& Jain (2008) & Exponential smoothing weight \\
\hline Hadi-Vencheh (2010) & \\
\hline Rezaei \& Dowlatshahi (2010) & \\
\hline
\end{tabular}

\begin{tabular}{|l|l|}
\hline & \\
\hline Reference & \\
\hline Chen(2011) & Peer-estimation approach \\
\hline Hadi-Vencheh \& Mohamadghasemi (2011) & Fuzzy AHP-DEA \\
\hline Yu(2011) & Artificial neural network (ANN) \\
\hline Chen(2012) & Two virtual items and TOPSIS idea \\
\hline Torabi et al.(2012) & Modified model to Hadi-Vencheh (2010) \\
\hline Aydin Keskin \& Ozkan (2013) & Fuzzy c-means (FCM) clustering \\
\hline Mohammaditabar et al. (2012) & Simulated annealing \\
\hline Kabir\& Akhtar Hasin (2013) & Fuzzy AHP and ANN \\
\hline Hatefi et al. (2014) & Modified linear optimisation \\
\hline Lolli et al. (2014) & AHP-K and AHP-K-Veto \\
\hline Park et al. (2014) & Cross-evaluation based weighted linear optimization \\
\hline Soylu \& Akyol (2014) & UTADIS \\
\hline Liu et al. (2016) & Ladhari et al. (2016) \\
\hline
\end{tabular}


Appendix B: Spare parts classification criteria

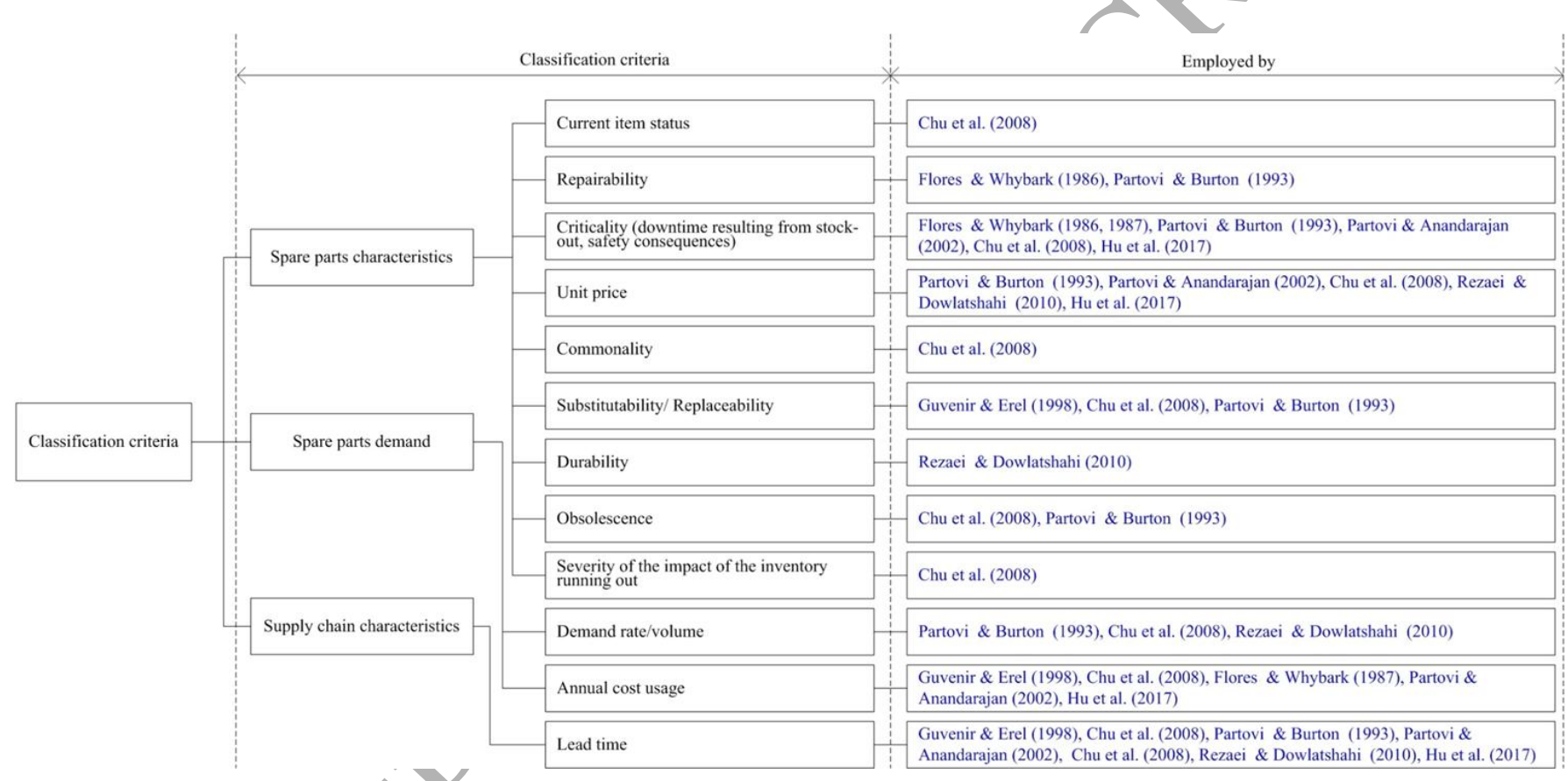

